\title{
Prediction of Moderate and Heavy Rainfall in New Zealand Using Data Assimilation and Ensemble
}

Yang Yang, Phillip Andrews, Trevor Carey-Smith, Michael Uddstrom, and Mike Revell

National Institute of Water and Atmospheric Research (NIWA), Private Bag 14901, Wellington 6021, New Zealand

Correspondence should be addressed to Yang Yang; y.yang@niwa.co.nz

Received 7 December 2014; Accepted 5 February 2015

Academic Editor: Yuanfu Xie

Copyright () 2015 Yang Yang et al. This is an open access article distributed under the Creative Commons Attribution License, which permits unrestricted use, distribution, and reproduction in any medium, provided the original work is properly cited.

\begin{abstract}
This numerical weather prediction study investigates the effects of data assimilation and ensemble prediction on the forecast accuracy of moderate and heavy rainfall over New Zealand. In order to ascertain the optimal implementation of state-of-the-art 3Dvar and 4Dvar data assimilation techniques, 12 different experiments have been conducted for the period from 13 September to 18 October 2010 using the New Zealand limited area model. Verification has shown that an ensemble based on these experiments outperforms all of the individual members using a variety of metrics. In addition, the rainfall occurrence probability derived from the ensemble is a good predictor of heavy rainfall. Mountains significantly affect the performance of this ensemble which provides better forecasts of heavy rainfall over the South Island than over the North Island. Analysis suggests that underestimation of orographic lifting due to the relatively low resolution of the model $(\sim 12 \mathrm{~km})$ is a factor leading to this variability in heavy rainfall forecast skill. This study indicates that regional ensemble prediction with a suitably fine model resolution $(\leq 5 \mathrm{~km})$ would be a useful tool for forecasting heavy rainfall over New Zealand.
\end{abstract}

\section{Introduction}

The initial conditions of a numerical weather prediction (NWP) forecast are usually generated by data assimilation, a procedure statistically combining observations and a model forecast and utilising their respective error information to create an optimum estimate of the true atmospheric state compatible with the forecast model in use. Uncertainty and errors are unavoidable in the initial conditions of an NWP due to meteorological equipment errors, sampling errors, and data assimilation errors, and so forth. Ensemble forecasts have been used for some 20 years at major meteorological prediction centres to explore the impact of these uncertainties in the atmospheric initial conditions (and other boundary conditions) on NWP. Several methodologies have been used to establish the global ensemble systems (GES) including those based on the leading singular vectors of the operator $[1,2]$, bred vectors [3, 4], the Monte Carlo method [5], and the Monte Carlo based ensemble Kalman filter [6].

The spatial resolution of currently operational GES is low (e.g., $\sim 32 \mathrm{~km}$ for the current operational ECMWF ensemble system). Many small scale processes in the atmosphere and the underlying surface and small scale mountains that significantly affect the evolution and development of severe weather are not resolved by GES. Regional ensemble systems (RES) were thus established. The resolution of RES differs. Some have very high resolutions so that supercell storms and convections can be resolved (e.g., [7-9]). The way to initialize a RES also differs. Some RESs are initialized from a GES. Some RESs randomly sample the climatological uncertainties of the initial state [10]. Others derive random perturbations from the background error statistics of an existing $3 \mathrm{D} / 4 \mathrm{Dvar}$ system (e.g., [11-13]). Some RESs use different model physics and different global deterministic model outputs to generate members (e.g., $[14,15])$. Some use different regional model outputs called multimodel ensemble [16]. For heavy rainfall forecasts, RES has shown higher forecasting skills than GES (e.g., $[14,17,18])$.

New Zealand lies in the midlatitude southwest Pacific, surrounded by ocean. The two main islands are North Island and South Island. North Island (Figure 1(a)) has a "spine" of mountain ranges extending from the middle, with gentle rolling farmland on both sides. The South Island is dominated by mountain ranges running its entire length. The main 
$\mathrm{MM}$, total rain for 35 days $(\mathrm{mm})$, north island

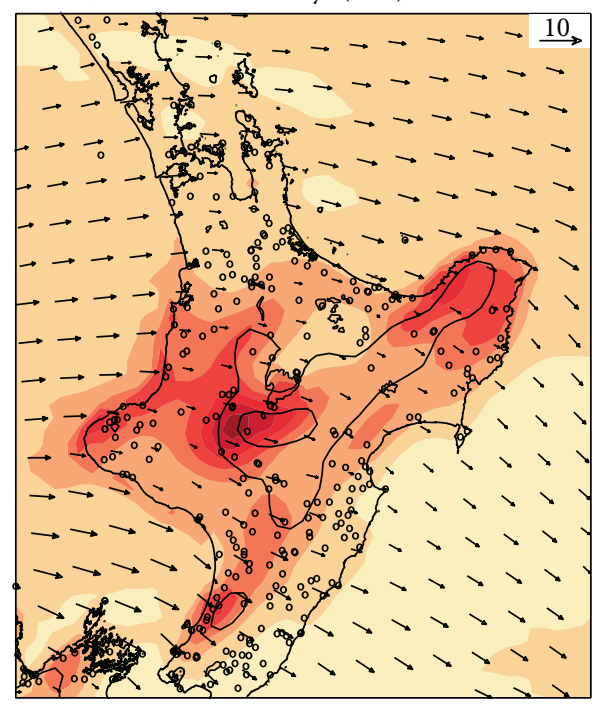

(a)

$\mathrm{MM}$, total rain for 35 days $(\mathrm{mm})$, south island

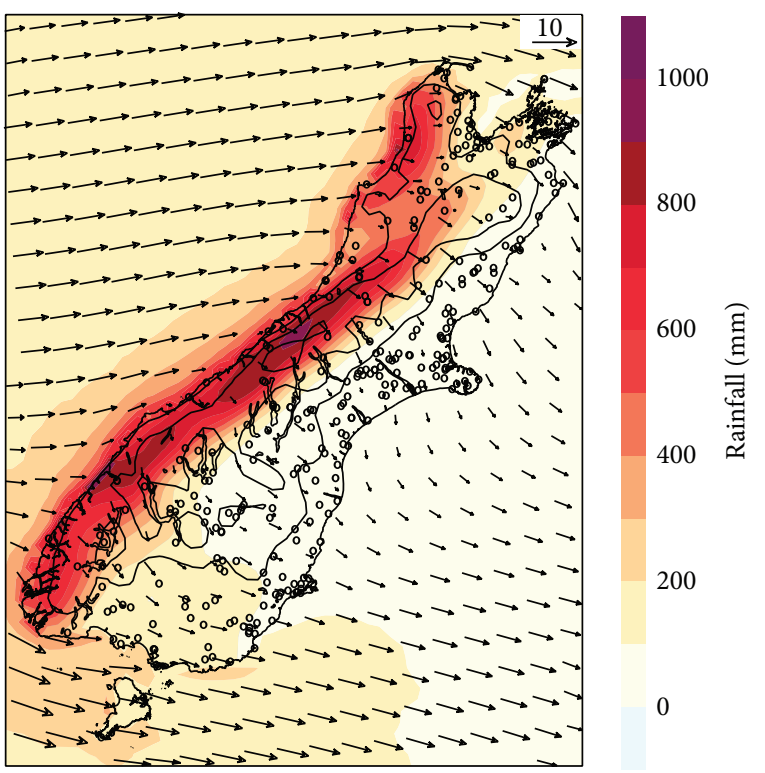

(b)

Figure 1: Total rainfall amount $(\mathrm{mm})$ and mean surface wind vectors $\left(\mathrm{m} \mathrm{s}^{-1}\right)$ of 35 days from 13 Sept to 18 Oct 2010 for the ensemble mean. The 630 sites with daily rainfall observations used in this study are denoted with open dots. Thin solid lines denote the model terrain contours of $500 \mathrm{~m}$ interval. Note the different scales for the two rainfall labels.

mountain range with a southwest to northeast orientation is known as the Southern Alps (Figure 1(b)). Under the prevailing midlatitude westerly winds, the western region of New Zealand is generally the windward side and the eastern region is the lee side.

Rainfall amount is much higher over land areas than over the nearby sea because of orographic lifting (Figure 1). Overall, much more rainfall occurs in the western area of the South Island than on other areas of the country, because of orographic lifting of more consistent westerly airflows and more uniform mountains. Heavy rainfall often leads to severe flooding and landslides in New Zealand. Thus, a reliable heavy rainfall prediction is of great importance but still a big challenge, largely due to the open seas surrounding the small island country with sparse ground-based/surface observations and rawinsondes. To overcome the problem of lack of meteorological observations for New Zealand, satellite data have been widely used in a regional 3Dvar system based on the New Zealand limited area model (NZLAM, $[19,20])$ for a 48 -hour NWP in New Zealand. This has shown improvements [21].

4Dvar has been implemented at some major meteorological centres (e.g., Met Office and ECMWF) to replace 3Dvar. Their verification statistics show an overall higher forecasting skill for 4Dvar (e.g., [22]). Recently an experimental regional 4 Dvar for NZLAM has been set up from the UK Met Office VAR codes. To compare the impact on the forecasts of the 3 Dvar and 4Dvar data assimilation methods, to tune the $4 \mathrm{Dvar}$ for the best possible result, and to test the impact of new observation types (e.g., surface marine observations) on both analysis methods, 12 numerical experiments based on NZLAM were conducted over the period of 35 days from 13 September to 18 October 2010 (Table 1). Each experiment differs in either the analysis system, or system configuration, or the surface and satellite data assimilated.

In this study, a temporary RES was created by combining 12 experiments originally intended to compare the impact of the 3Dvar and 4Dvar techniques on the skill of NZLAM forecasts. Although the principal behind this ensemble is similar to ensemble systems which use different model physics or/and different regional/global deterministic model outputs [14-16], members of this ensemble system employed the state-of-the-art 3Dvar and 4Dvar techniques in assimilating satellite data [22]. To our knowledge, this is the first attempt at predicting heavy rainfall in New Zealand using a RES.

The objective of this study is to investigate the effect of data assimilation and ensemble method on moderate and heavy rainfall prediction over New Zealand. Of particular interest is how mountains affect the performance of a RES in prediction of moderate and heavy rainfall and therefore the suitable model resolution for a RES over New Zealand. Following the introduction, the modelling system and methodology are described in Section 2. Two heavy rainfall cases forecasted by this RES are described in Section 3. Statistical analysis regarding the performance of this RES is presented in Section 4 . The effect of mountains on this RES is discussed in Section 5. Finally a short conclusion is given in the last section.

\section{Description of the Modelling System and Methodology}

All the simulations in this study were made by using the NZLAM, a regional configuration of the Met Office's Unified Model (UM, [23]). The UM has a nonhydrostatic, fully compressible formulation of the Navier-Stokes equations using a terrain following, height-based vertical coordinate. 
TABLE 1: Description of the 12 ensemble members used in this study.

\begin{tabular}{ll}
$\begin{array}{l}\text { Member } \\
\text { names }\end{array}$ & Description \\
\hline 3Dvar & $\begin{array}{l}\text { 3D analysis of surface (including buoys; land synops; ship synops and scatterometer winds), aircraft and radiosondes, } \\
\text { AMSU-A, and AMSU-B from the NOAA-15 and NOAA-16 satellites. Half resolution of the model for the analysis grid } \\
\text { (0.22 degrees). }\end{array}$ \\
\hline 3Dcli & As 3Dvar but also analyse additional surface observations at climate stations in New Zealand. \\
\hline 3Dclim & As 3Dcli but also analyse surface marine observations. \\
\hline 3DclimB & As 3Dclim but uses satellite radiance bias corrections calculated from the 3dclim run. \\
\hline 3DclimC & As 3DclimB but with increased satellite-derived atmospheric motion vectors (AMV) usage through modified \\
\hline 4Dvarli & As 3Dvar but for 4Dvar with analysis grid resolution the same as the model (0.11 degrees). \\
\hline 4D1la & As 4dvarll but exclude scales <50 km during analysis. \\
\hline 4D11b & As 4dvarll but exclude scales <100 km during analysis. \\
\hline 4Dcli & As 4D1la but also analyse additional surface observations at climate stations in New Zealand. \\
\hline 4Dclim & As 4Dcli but also analyse surface marine observations. \\
\hline 4DclimB & As 4Dclim but uses satellite radiance bias corrections calculated from the 4dclim run. \\
\hline 4DclimC & As 4DclimB but with increased AMV usage through modified thinning. \\
\hline
\end{tabular}

It employs a horizontally staggered Arakawa C-grid and a vertically staggered Charney-Phillips grid; semi-Lagrangian advection for all prognostic variables, except density, with conservative and monotone treatment of tracers; predictorcorrector implementation of a two-time-level, semi-implicit time integration scheme; and three-dimensional iterative solution of a variable-coefficient elliptic equation for the pressure increment at each time step (see $[23,24]$ for detailed descriptions). The NZLAM has 324 by 324 horizontal grid points with a horizontal grid spacing of $0.11^{\circ}$ (about $12 \mathrm{~km},[19$, 20]) and 70 levels in the vertical, with the model top at about $39 \mathrm{~km}$. The highest vertical resolution is near the ground such that 20 levels span the lowest $2 \mathrm{~km}$ of the atmosphere. A global run provided the same lateral boundary conditions for all the ensemble simulations.

All the experiments were classified as two groups with initializations based on 3Dvar (five members) and 4Dvar (seven members), respectively (Table 1). The former uses an incremental 3Dvar FGAT (first guess at appropriate time) analysis scheme [25]. The latter is based on the former with many aspects kept in common and is provided by the introduction of a linear perturbation forecast model and its adjoint [22]. In both schemes, a transform (including a parameter transform, a vertical transform, and a horizontal transform) is implemented to provide an implicit representation of the background error covariance and a practical and easy method of preconditioning the analysis minimisation problem. For the five 3Dvar-based members, the analysis resolution used ( 0.22 degrees) is half the model resolution, whilst, for the seven $4 \mathrm{Dvar}$-based members, the resolution is the same as the model resolution (Other experiments, not presented here, have shown that using full or half resolution analysis increments for 3Dvar makes very little difference to the verification scores against observations for forecasts out to $\mathrm{T}+48$; however, using lower resolution analysis increments for 4 dvar significantly reduces forecast skill.) (Table 1).
The vertical transform uses zonal and seasonal average statistics to produce two-dimensional empirical modes. The horizontal transform can also be used as a filter, to remove small scale modes from each horizontal field. Following the ideas of Cullen [26] we used this to exclude scales smaller than $50 \mathrm{~km}$ for $4 \mathrm{D} 11 \mathrm{a}$ and smaller than $100 \mathrm{~km}$ for $4 \mathrm{D} 11 \mathrm{~b}$, 4Dcli, 4Dclim, 4DclimB, and 4DclimC. Both 3D and 4Dvar performed a 6 hourly data assimilation cycle throughout the study period. After 0000 UT on 13 September 2010 (the initial time for each experiment), the background used for the analysis for each experiment differed to some extent. 48hour forecasts were made following the 0000, 0600, 1200, and 1800 UT analyses for each experiment each day and simulated fields were saved hourly.

The ensemble mean was calculated with an equal weight for each member. In addition to root mean square errors (RMSE) and mean errors (ME), categorical forecasts at the two thresholds were examined using the performance diagram [27] and relative operating characteristic (ROC) diagram. The performance diagram plots the hit rate $(H)$ against the success ratio ( 1 - FAR, the false alarm ratio) and allows the bias and critical success index (CSI) to be read directly. The ROC diagram plots the hit rate against the false alarm rate $(F)$ from which it is easier to deduce base rate independent performance metrics such as the Peirce skill score (PSS) or symmetric extreme dependence index (SEDI). The latter measure is useful for rare events as it is nondegenerate [28]. Definitions for these categorical metrics are given in Table 2 .

In the following calculation and analysis, all four forecasts on each day for each member during the 35 days were used. For each forecast, the forecast rainfall was chosen to match the observations in time. The rainfall forecast at the four grid points surrounding an observation site was linearly interpolated onto that site using distance as the weighting factor. 
TABLE 2: Categorical measures used in this study along with their definitions based on a binary truth table, where $a$ is the number of events which were forecast correctly, $c$ the number of observed events not forecast, $b$ the number of nonevents incorrectly forecast, and $d$ the number of nonevents correctly forecast.

\begin{tabular}{|c|c|c|}
\hline Metric & Formula & Range \\
\hline Frequency bias & Bias $=\frac{a+b}{a+c}$ & 0 to $\infty$ (perfect: 1$)$ \\
\hline Hit rate & $H=\frac{a+c}{a+c}$ & 0 to 1 (perfect: 1 ) \\
\hline False alarm rate & $F=\frac{b}{b+d}$ & 0 to 1 (perfect: 0 ) \\
\hline False alarm ratio & $\mathrm{FAR}=\frac{b}{a+b}$ & 0 to 1 (perfect: 0 ) \\
\hline Critical success index & $\mathrm{CSI}=\frac{a}{a+b+c}$ & 0 to 1 (perfect: 1 ) \\
\hline Peirce skill score & PSS $=\frac{a d-b c}{(b+d)(a+c)}$ & -1 to 1 (perfect: 1 ) \\
\hline Symmetric extremal dependence index & $\mathrm{SEDI}=\frac{\ln F-\ln H+\ln (1-H)-\ln (1-F)}{\ln F+\ln H+\ln (1-H)+\ln (1-F)}$ & -1 to 1 (perfect: 1 ) \\
\hline
\end{tabular}

\section{Two Heavy Rainfall Cases}

Daily rainfall analysis with 0.05 -degree resolution over New Zealand land surface is available at the National Institute of Water and Atmosphere Research (NIWA) derived using the second order derivative trivariate thin plate smoothing spline spatial interpolation model (http://www.maths.anu.edu.au/ research/projects/thin-plate-splines). These data may have some errors and uncertainties in mountainous areas with sparse observations, but they are the best high resolution grid point rainfall data over New Zealand. These data are compared with forecasted rainfall by the ensemble for two heavy rainfall cases.

For Case 1, a subtropical cyclone with a tropical origin moved southeastward and approached the nearby sea to the northeast of the North Island in the early morning of 13 October 2010 (Figure 2(a)). A warm front (denoted by "WARM F") associated with the cyclone moved southwestward in the northeasterly winds of the cyclone. Ahead of the warm front were southeasterly winds. The warm front reached the southeast coastal region of the North Island on the morning of 13 October. Orographic lifting of the strong southeasterly winds $\left(10-15 \mathrm{~m} \mathrm{~s}^{-1}\right.$ surface winds at a coastal station) ahead of the warm front enhanced vertical motion in the frontal rainband. This led to very heavy rainfall in a broad area of the southeast North Island (Figure 3(a)). The rainfall analysis showed a rainband with four rainfall maximum centers from northeast to southwest. At some locations, the observed 24-hour rainfall at 0900 NZST on the 14 October was about $190 \mathrm{~mm}$. Figure 3(c) shows the 24-hour rainfall forecast by the ensemble mean using equal weight. Most of the heavy rainfall areas were captured by the ensemble mean. However, the ensemble missed two of the four rainfall maximum centers: the southernmost one and the one in the middle of the rainband. For the two rainfall maximum centers captured by the ensemble, the maximum was $25-50 \mathrm{~mm}$ lower than observations. The terrain data in Figure 3(a) with a resolution of roughly $5 \mathrm{~km}$, much higher than the model terrain (Figure $3(\mathrm{c}$ ), roughly $12 \mathrm{~km}$ resolution), can describe smaller mountains. For example, a small mountain is shown in Figure 3(a) associated with the southernmost rainfall maximum center, but not shown by the model terrain (Figure 3(c)). The mountain corresponding to the rainfall maximum center in the middle of the rainband (Figure 3(a)) is more pronounced and higher than that in the model terrain (Figure 3(c)). For this heavy rainfall case, the convective available potential energy (CAPE) was very small $\left(<100 \mathrm{~J} \mathrm{~kg}^{-1}\right)$, implying a very weak contribution from convective rainfall and a correspondingly stronger orographic component. It appears that the underestimation of the heavy rainfall by the ensemble is partly due to the relatively low resolution of the model, which underestimates the orographic lifting. This will be further analysed in Sections 4.2 and 5 .

The forecast occurrence of daily rainfall greater than $50 \mathrm{~mm}$ with probability higher than 0.6 (Figure $4(\mathrm{c})$ ) captured most of the areas with observed daily rainfall greater than $50 \mathrm{~mm}$ (Figure 4(a)). Most of the areas in the southeast of the North Island had a daily rainfall greater than $100 \mathrm{~mm}$ for this heavy rainfall case (Figure 4(b)). However, less than half of these areas were forecast to get greater than $100 \mathrm{~mm}$ with occurrence probability higher than 0.6 (Figure $4(\mathrm{~d})$ ) by the ensemble. This is due to the underestimation of rainfall by the model.

For Case 2, on 28 September 2010, an eastward moving midlatitude cyclone was over the sea to the southwest of the South Island (Figure 2(b)). The westerly winds associated with the cyclone advected the cold front (denoted by "COLD F") eastward. Ahead of the cold front were northwesterly winds. When the cold front reached the South Island, orographic lifting and island blocking of the strong northwesterly and westerly winds around the front enhanced the vertical motion in the associated rainband, leading to heavy rainfall on the windward (western) areas of the South Island on that day (Figure 3(b)). The ensemble mean generally forecast well the heavy rainfall amount and distribution, except that it missed the heavy rainfall at the southern end of the rainband (Figure 3(d)). The ensemble based forecast occurrence of daily rainfall greater than $50 \mathrm{~mm}$ with probability higher 


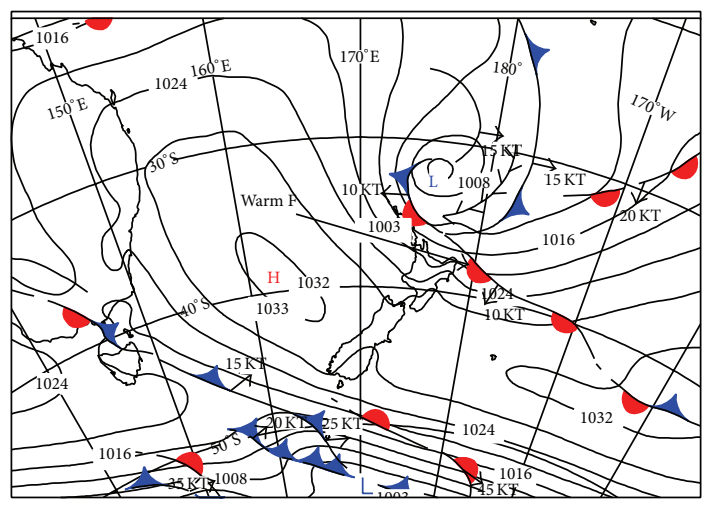

(a)

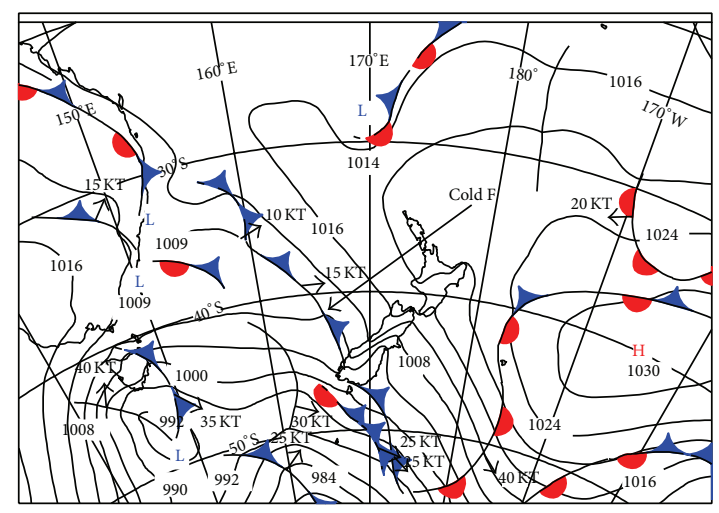

(b)

Figure 2: Surface analysis by MetService New Zealand at (a) 0000 NZST 13 October 2010 and (b) 1800 NZST 28 September. "WARM F" in (a) points to the warm front and "COLD F" in (b) points to the cold front. New Zealand lies in the middle of each diagram. Curtesy to MetService New Zealand.

24-hour rainfall to 0900 NZST 14 Oct 2010

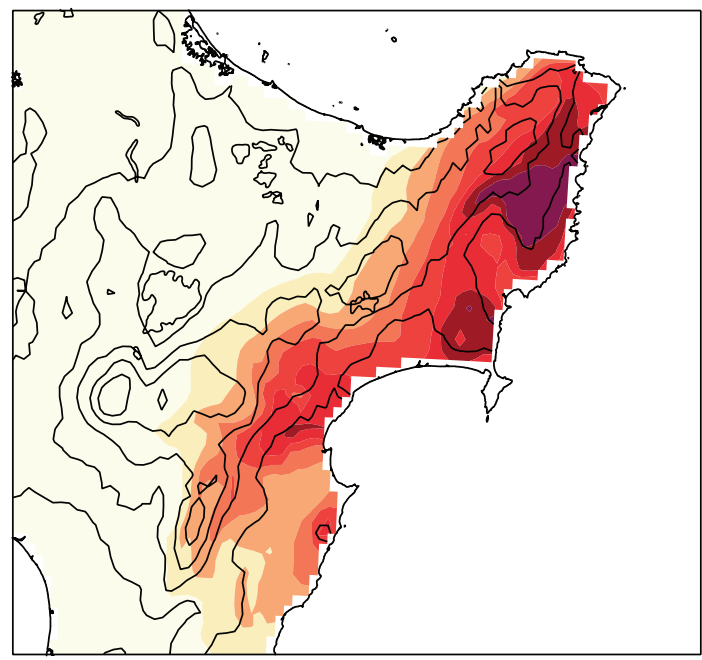

(a)

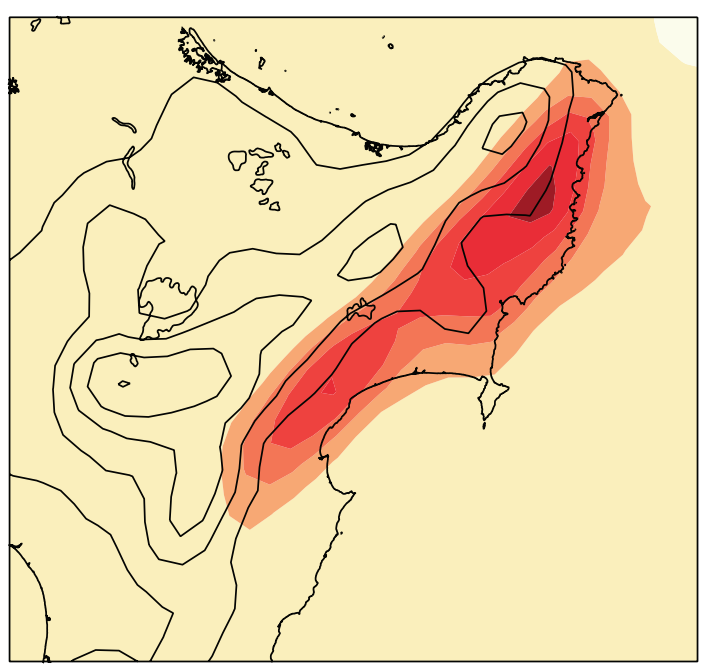

(c) 24-hour rainfall to 0900 NZST 29 Sept 2010

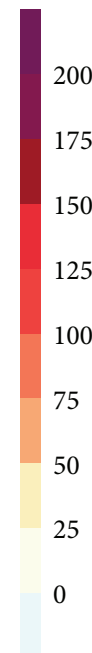

200
175
50
25
00
75
50
0

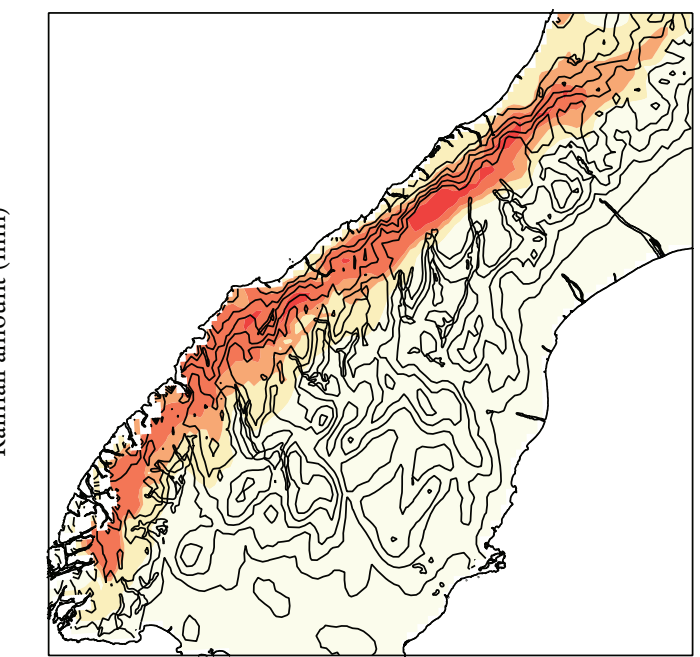

(b)

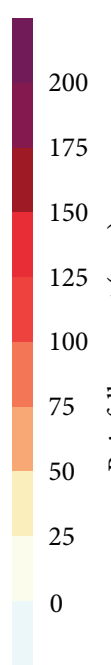

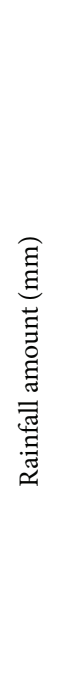

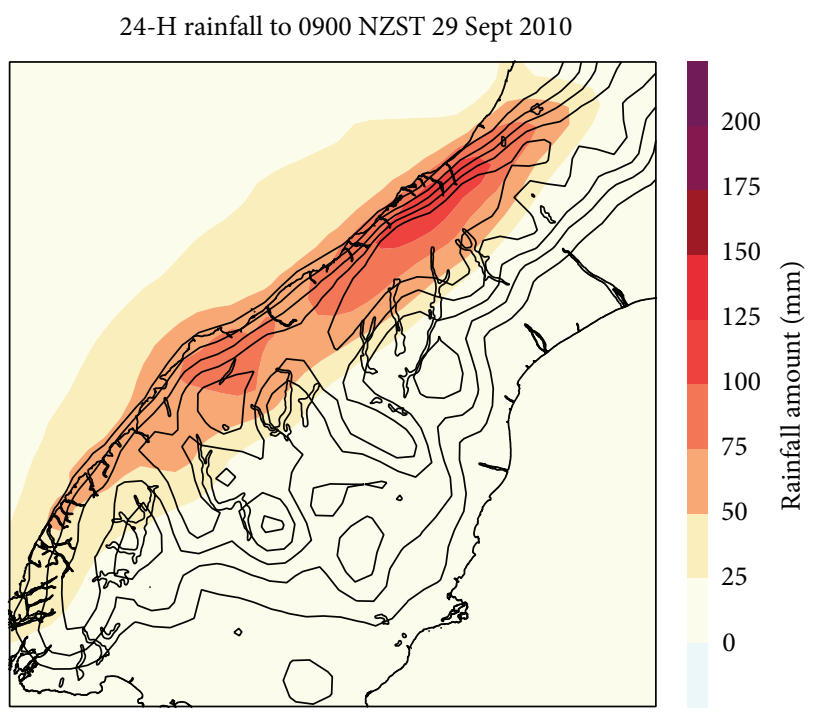

(d)

FIGURE 3: 24-hour rainfall amount (mm) valid at (a) 0900 NZST 14 October 2010 and (b) 0900 NZST 29 September from NIWA 0.05-degree grid point rainfall analysis. Simulated 24-hour rainfall amount valid at (c) 0900 NZST 14 October 2010 and (d) 0900 NZST 29 September from the ensemble mean (MM) forecasts with analysis at 0006 NZST. Thin solid lines denote terrain contours with a 250-meter interval. 


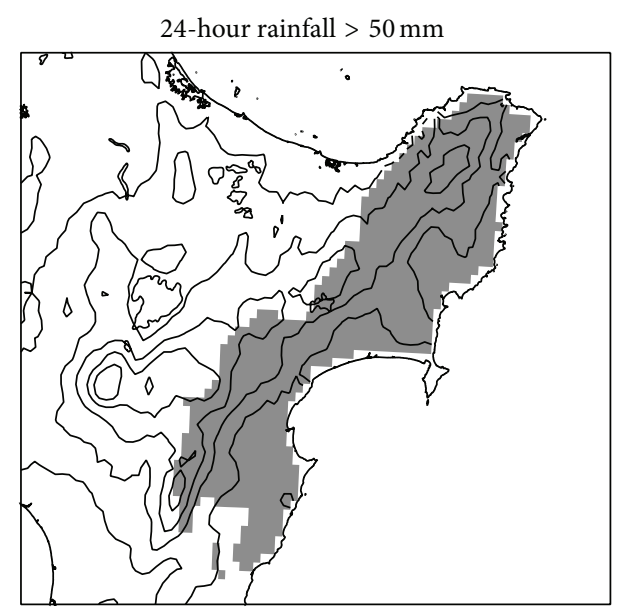

(a)

Probability of 24-hour rainfall $>50 \mathrm{~mm}$

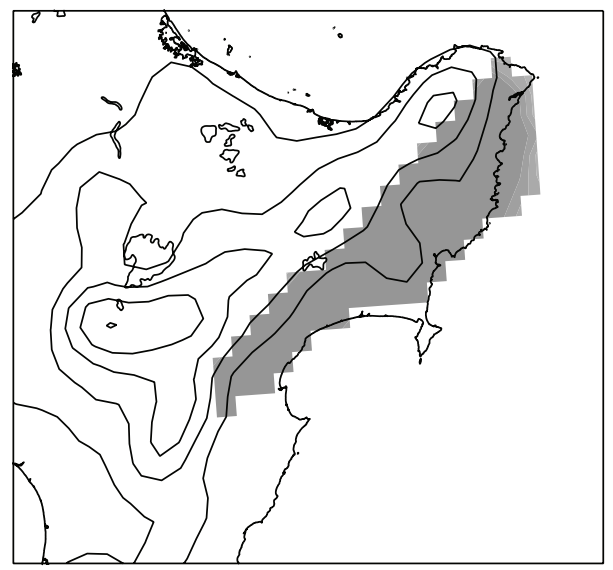

(c)
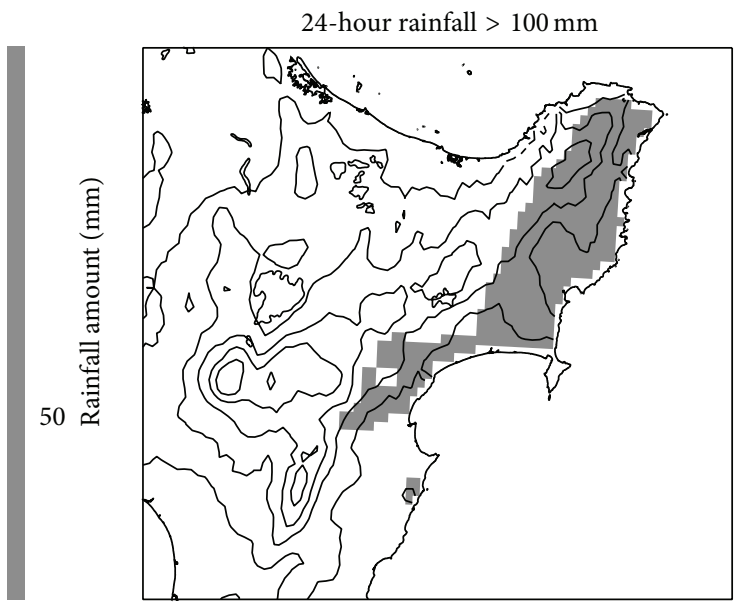

(b)

Probability of 24-hour rainfall > $100 \mathrm{~mm}$

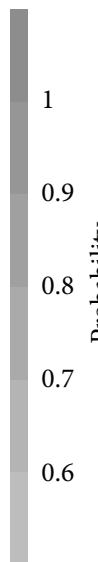

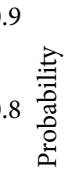

0.7

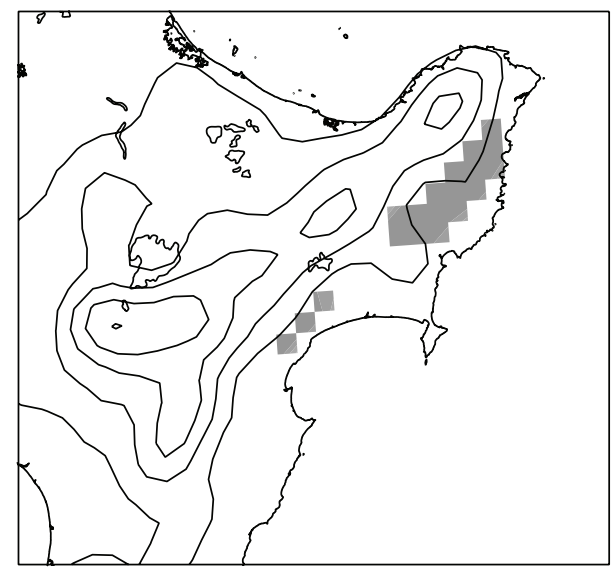

(d)

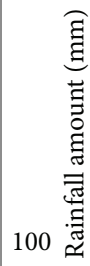

0.9

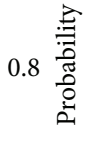

0.7

0.6

FIGURE 4: 24-hour rainfall amount (mm) valid at 0900 NZST 14 October 2010 greater than $50 \mathrm{~mm}$ (a) and $100 \mathrm{~mm}$ (b) from NIWA 0.05-degree grid point rainfall analysis. Occurrence probability higher than 0.6 for the corresponding forecasted 24-hour rainfall greater than $50 \mathrm{~mm}$ (c) and $100 \mathrm{~mm}$ (d) with analysis at 0600 NZST. Thin solid lines denote terrain contours with a 250-meter interval.

than 0.6 , a large area on the windward side of the South Island (Figure 5(c)), corresponded well to most of the areas with observed daily rainfall greater than $50 \mathrm{~mm}$ (Figure 5(a)). Observed daily rainfall greater than $100 \mathrm{~mm}$ occurred only over a small area on the windward side (Figure 5(b), the small shading area in the circle). The ensemble based forecast of daily rainfall amount greater than $100 \mathrm{~mm}$ with probability equal to 0.6 also showed a small area (Figure 5(d), the shading area in the circle) close to that in Figure 5(b).

These analyses suggest that probability of greater than 0.6 of occurrence of rainfall greater than some threshold from the ensemble is a good predictor for heavy rainfall in New Zealand. Compared with Case 1, the ensemble performed better for Case 2, especially for daily rainfall greater than $100 \mathrm{~mm}$. In fact, using the 0.05 -degree grid point rainfall analysis, the RMSE of the ensemble mean for daily rainfall greater than $50 \mathrm{~mm}$ was $78 \mathrm{~mm}$ and $111 \mathrm{~mm}$ for Case 2 and for Case 1, respectively. The reason for the better performance of the heavy rainfall forecast over the South Island by the ensemble will be further analysed in Sections 4.2 and 5 .

\section{Statistical Analysis}

In this section, the ensemble RMSE, ME, and categorical skill scores for two rainfall categories are presented. The first category includes events in which either simulated or observed daily rainfall is equal to or higher than $50 \mathrm{~mm}$ (also called heavy rainfall). Because there were only 35 days for each experiment, a second threshold of $20 \mathrm{~mm} /$ day (modheavy rainfall) was chosen to ensure a sample size sufficient for statistically robust results. Daily rainfall observations (valid at 0900 NZST) at 630 sites over New Zealand during the 35 days were used.

4.1. The Whole Country. The ability of the different ensemble members (and ensemble means) to correctly predict rainfall 
24-hour rainfall $>50 \mathrm{~mm}$

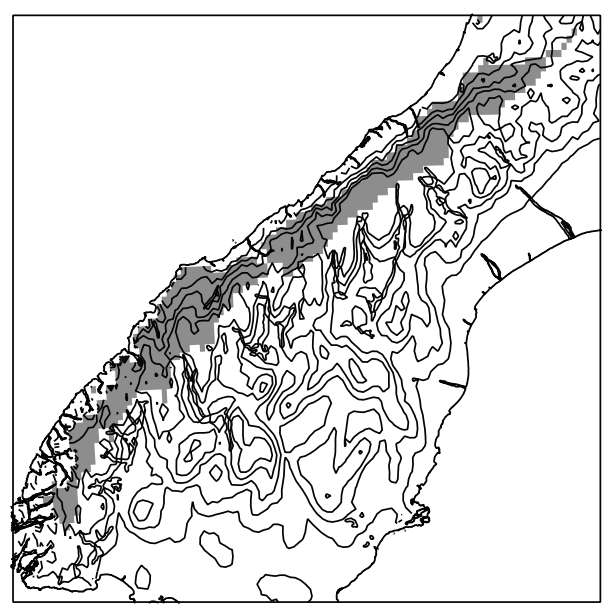

(a)

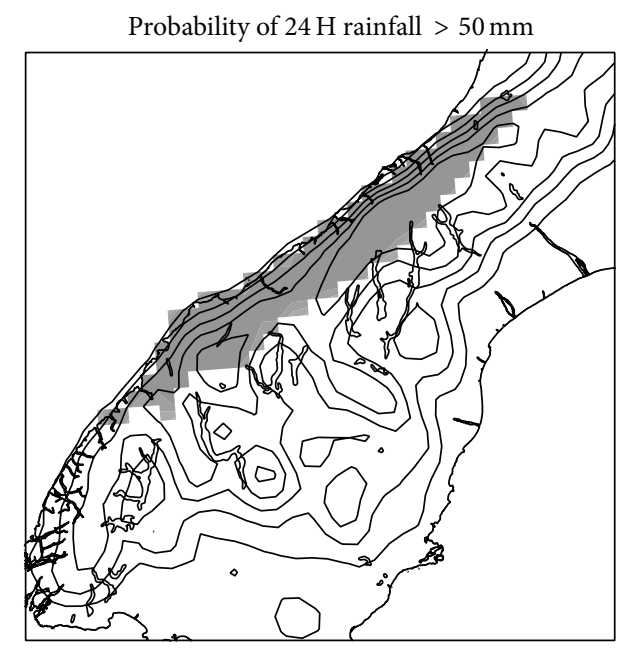

(c)

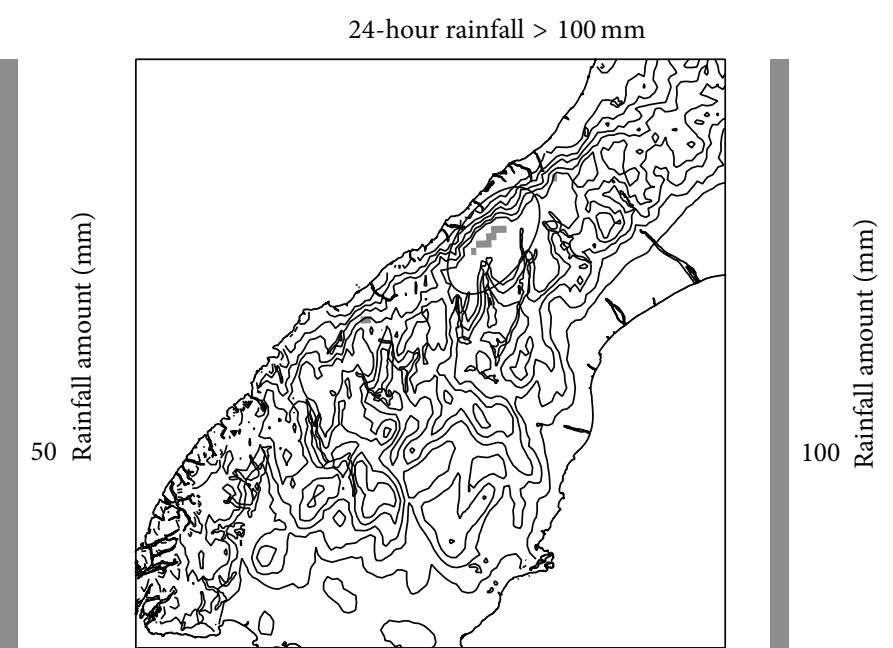

(b)

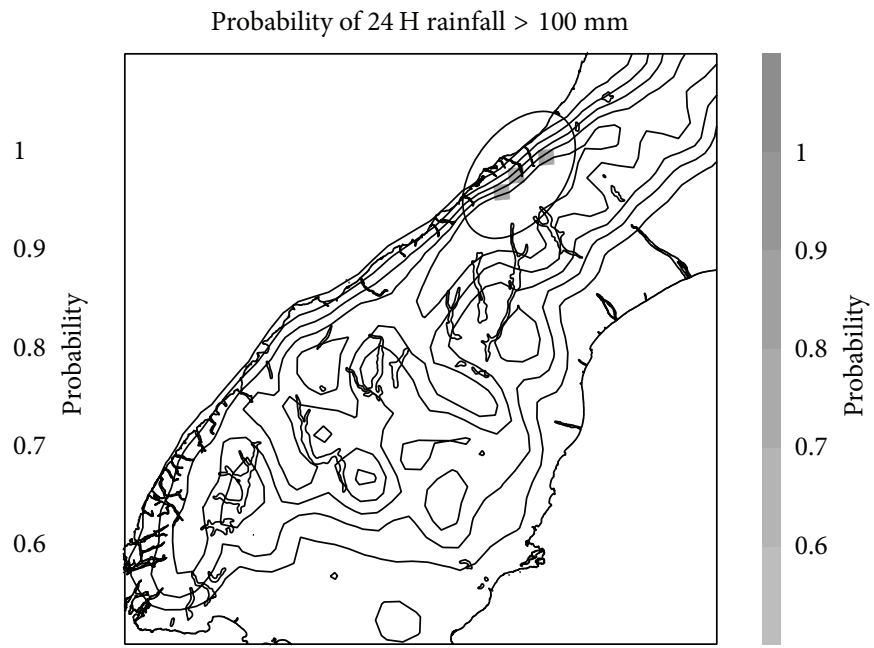

(d)

FIGURE 5: Same as Figure 3 but for 24-hour rainfall valid at 0900 NZST 29 September. Some shading areas in the circle of (b) had 24-hour rainfall greater than $100 \mathrm{~mm}$ and in the circle of (d) had occurrence probability higher than 0.6 for 24 -hour rainfall greater than $100 \mathrm{~mm}$.

TABLE 3: Contingency table for the ensemble mean (MM) for daily rainfall thresholds of $20 \mathrm{~mm}$ and $50 \mathrm{~mm}$ for the whole country (NZ), the North Island (NI), and the South Island (SI).

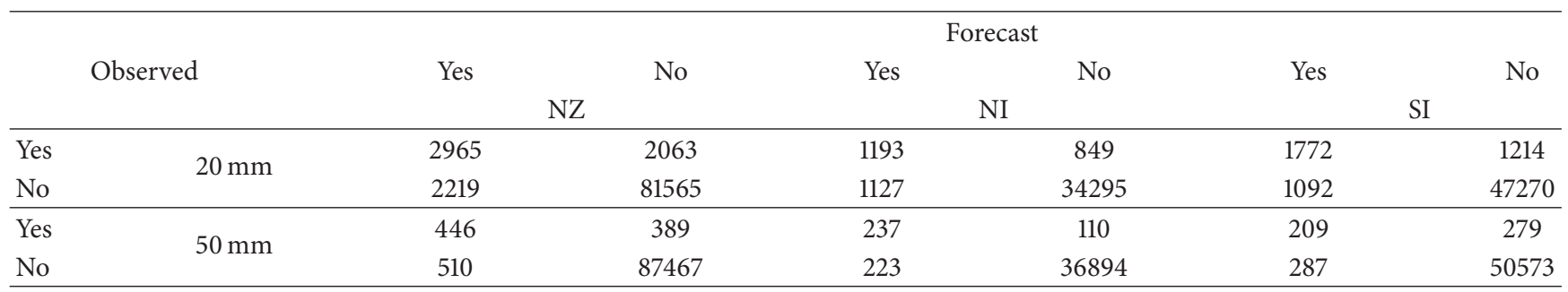

events for the two different thresholds was investigated by converting the forecasts and observations into binary events. Contingency tables for the ensemble mean (MM) at these two thresholds are shown in Table 3. Figure 6 shows the categorical performance diagram for mod-heavy and heavy rainfall over all of New Zealand. MM has the highest critical success index and the lowest false alarm ratio as compared with each member for both thresholds.

However, from Figure 6, it can be seen that the MM frequency bias for heavy rainfall is worse than for almost all of the individual members. That is, the improvement in FAR has not been matched by an improvement in hit rate, resulting in 


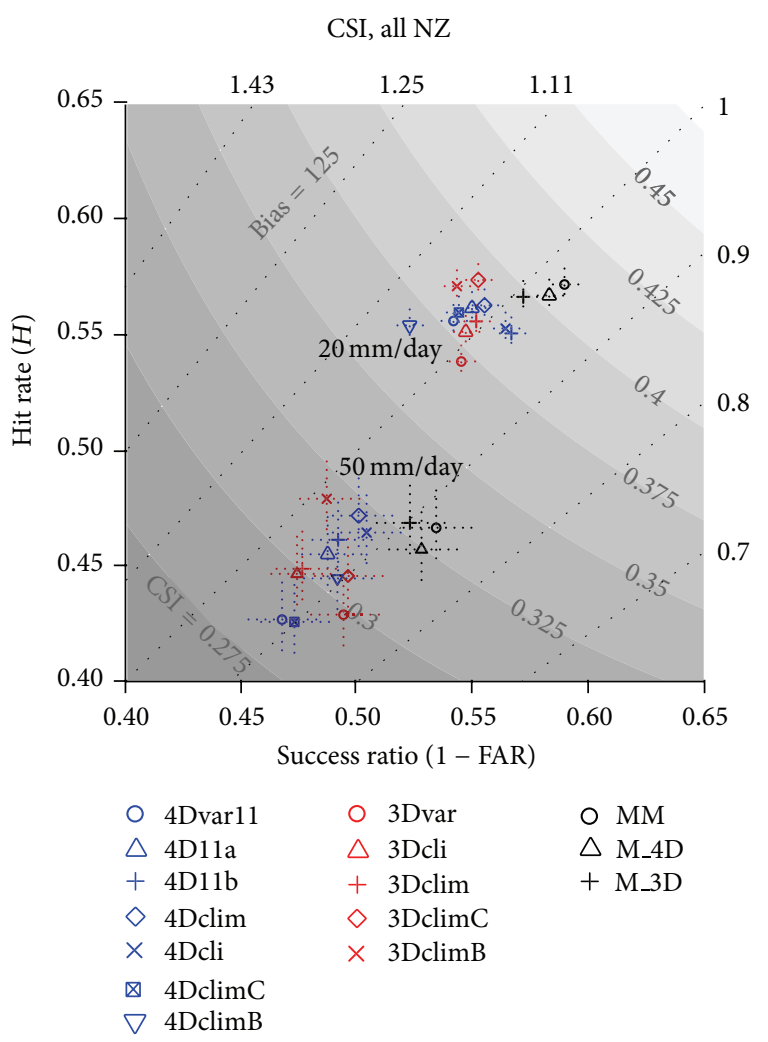

FIgure 6: Performance diagram comparing mod-heavy and heavy rainfall for all of NZ. CSI is shown by the shaded contours and bias by the grey dotted lines. The dotted uncertainty bars show the one standard deviation error in hit rate and success ratio.

a greater tendency for MM to underpredict the occurrence of heavy rainfall events. The ability to improve the CSI by hedging, that is, by reducing the frequency of forecasted events as outlined above, is one of the undesirable properties of the CSI. The Peirce skill score (PSS) is a categorical metric which does not have this property and is also base rate independent (insensitive to the sample climatology).

Peirce skill scores are shown in the ROC diagrams in Figures $7(\mathrm{a})$ and $7(\mathrm{c})$ which contain the mod-heavy and heavy rainfall results, respectively, for all of New Zealand. In contrast to CSI, PSS does not show the ensemble mean $\mathrm{MM}$ as being significantly better than any of the individual members. For the mod-heavy threshold, MM has the highest score, but it is the same as 3DclimC within uncertainties. For heavy rainfall, MM does not have the best PSS, but, within uncertainties, it is not worse than any of the individual members.

While it has many desirable properties, PSS is not always appropriate as it tends to meaningless values for vanishingly rare events (known as degeneracy). Ferro and Stephenson [28] developed the symmetric extremal dependence index (SEDI), in turn based on the extreme dependency score proposed by Stephenson et al. Both of these metrics are nondegenerate, but the SEDI has the advantage as it is base rate independent and difficult to hedge. Figures 7(b) and 7(d) contain the same data as Figures 7(a) and 7(c) except that the shading represents the SEDI instead of the PSS. From these diagrams it can be seen that, in contrast to the CSI and PSS, the magnitude of the SEDI is similar for both modheavy and heavy rainfall. In addition, the SEDI implies that for mod-heavy rainfall MM shows a larger improvement over the individual ensemble members and for heavy rainfall it is similar to the best performing members.

Figure 8 shows the RMSE over the whole country for all ensemble members. For mod-heavy rainfall, the RMSE of the ensemble mean (MM) was smaller than that of each member; the largest was $\sim 26.0 \mathrm{~mm}$ for $4 \mathrm{dvar} 11$, about $1.8 \mathrm{~mm}$ higher than MM. The difference in the RMSE between each member and MM was statistically significant at the $95 \%$ level using the $t$-test.

For heavy rainfall, the RMSE of the MM $(\sim 43 \mathrm{~mm})$ was smaller than that for all members except for 3Dcli $(\sim 43.0 \mathrm{~mm})$. The largest RMSE was $46.5 \mathrm{~mm}$ for 4dvarll, about $3.5 \mathrm{~mm}$ higher than the MM. Except for 3Dcli and $4 \mathrm{DclimB}$, the difference in the RMSE between each member (except for 3Dcli) and MM was statistically significant at $95 \%$ level using a $t$-test.

These results indicate that the ensemble mean is better than any of the individual ensemble members for forecasting mod-heavy rainfall over New Zealand. For heavy rainfall, the performance of the ensemble mean is better or similar to the best performing members. The small difference in the performance of the ensemble system between modheavy rainfall and heavy rainfall may be due to the smaller observation number for the latter (Table 3).

For the two daily rainfall categories, the mean errors (ME, forecast-observations) showed consistent negative values for each member (Figure 8(b)), especially for heavy rainfall, indicating that parts of the heavy rainfall forecast errors come from the negative bias. In addition to model physics, the relatively low model resolution $(\sim 12 \mathrm{~km})$ is most likely another reason for the underestimation of rainfall. This will be further analysed in the following section and Section 5 .

A possible reason for this improvement seen in the simple ensemble mean may be that it is simply due to the smoothing effect of calculating the mean of the 12 members. In other words, taking any member of the system and doing spatial smoothing, the improvement achieved might be as much as that from the ensemble mean. To investigate this possibility a 9-point smoother was applied three times to the rainfall forecast for each ensemble member and compared with the unsmoothed (Figure 9) via their RMSE. For modheavy rainfall, the 9-point smoother decreased the RMSE (Figure 9(a)) by $0.1-0.5 \mathrm{~mm}$ for each member. For MM, the smoother increased the RMSE by $\sim 0.2 \mathrm{~mm}$. The improvement of MM over each member was $0.5-1.6 \mathrm{~mm}$ for RMSE, much larger than that of each member achieved by the 9point smoother. In contrast, for heavy rainfall the smoother significantly increased the RMSE for each member and MM by $0.8-2.0 \mathrm{~mm}$. These facts indicate that the improvement of the simple ensemble mean in mod-heavy rainfall and heavy rainfall was mainly achieved from the simple ensemble system, not by the smoothing effect. 


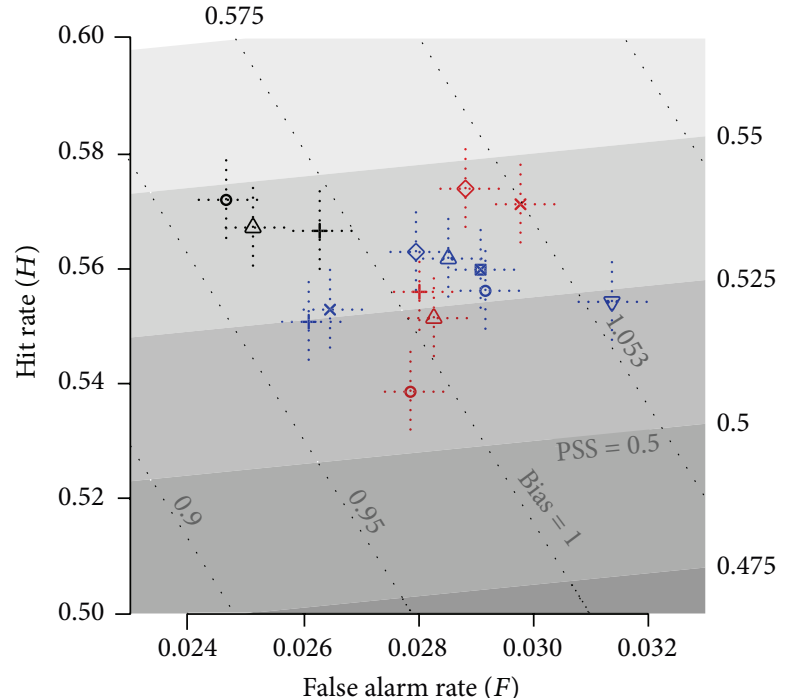

(a) PSS, $20 \mathrm{~mm} /$ day

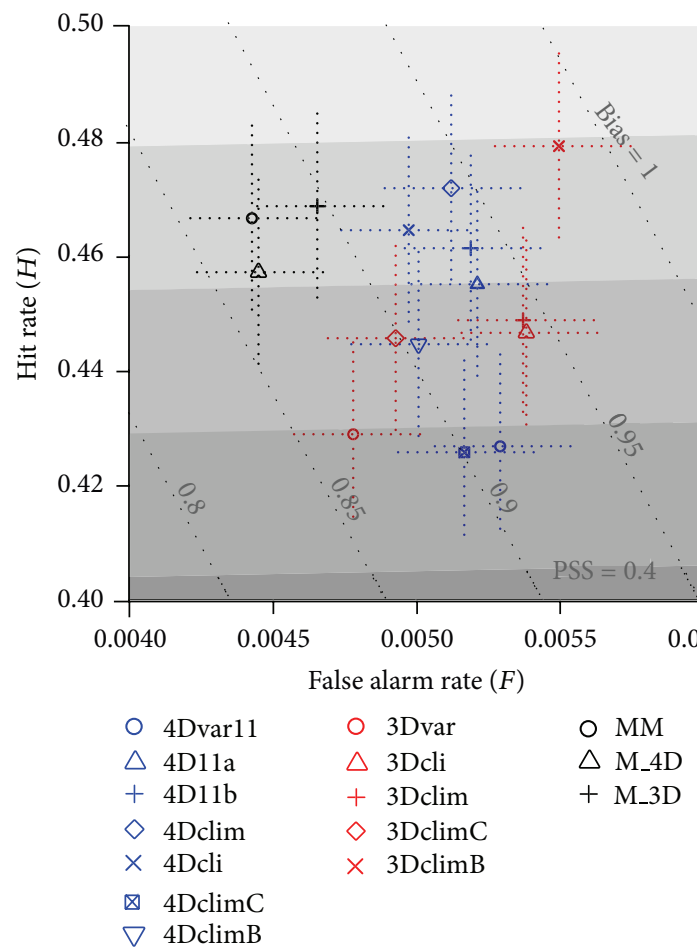

(c) PSS, $50 \mathrm{~mm} /$ day

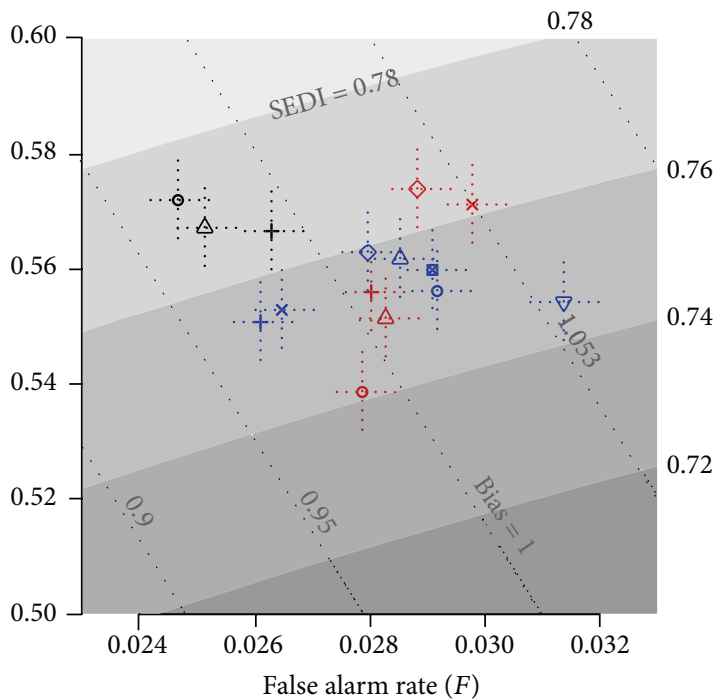

(b) SEDI, $20 \mathrm{~mm} /$ day

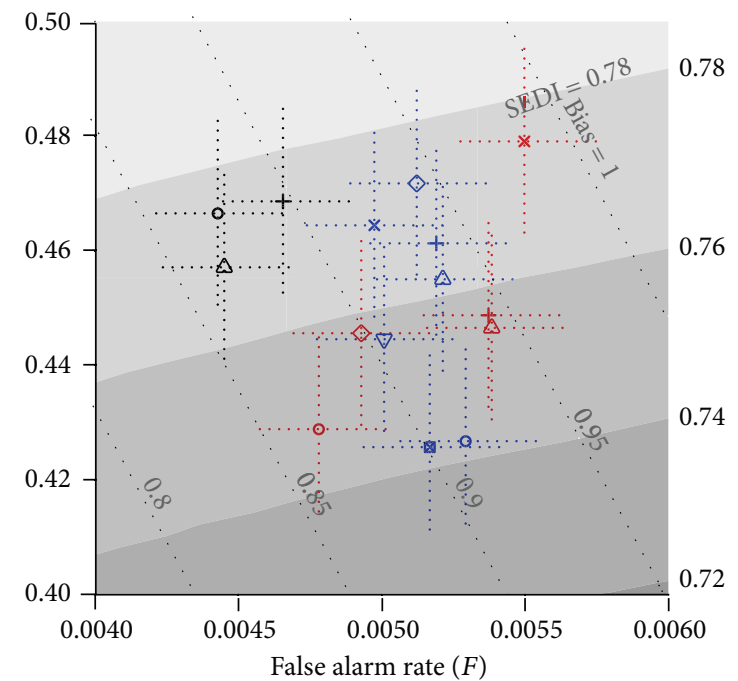

$\begin{array}{ll}\bigcirc 4 \text { Dvar11 } & \bigcirc 3 \text { Dvar } \\ \triangle 4 \text { D11a } & \triangle 3 \text { Dcli } \\ +4 \text { D11b } & +3 \text { Dclim } \\ \diamond 4 \text { Dclim } & \diamond 3 \text { DclimC } \\ \times 4 \text { Dcli } & \times 3 \text { DclimB } \\ \otimes 4 \text { DclimC } & \\ \nabla 4 \text { DclimB } & \end{array}$

(d) SEDI, $50 \mathrm{~mm} /$ day

FIGURE 7: Relative operating characteristic (ROC) diagrams including all of New Zealand for the mod-heavy (a and b) and heavy (b and c) rainfall thresholds. Bias is shown by the grey dotted lines and two different measures of forecast skill, PSS (a and c) and SEDI (b and d), are shown with shading.

4.2. Different Regions. The results for the North and South Island ensemble mean (MM) compared to the individual members are consistent with those found for the full country. That is the forecast skill of the MM, by various measures, and is similar to or better than any individual member and the frequency bias has been reduced compared to the majority of members (not shown).

The RMSE and ME of the North and South Island results for the subset of events that were forecast correctly or observed are shown in Figure 10 for mod-heavy rainfall and Figure 11 for heavy rainfall. For the North Island at both rainfall thresholds, MM has the lowest RMSE and for the South Island only 3Dcli has a lower RMSE than MM.

Here, a question needs to be answered is in which island (the North Island versus the South Island) the performance of the ensemble is better? The total number of rainfall observation sites and heavy rainfall observations were different between the two islands. It is not appropriate to use 
For daily rain $\geq 20 \mathrm{~mm}$

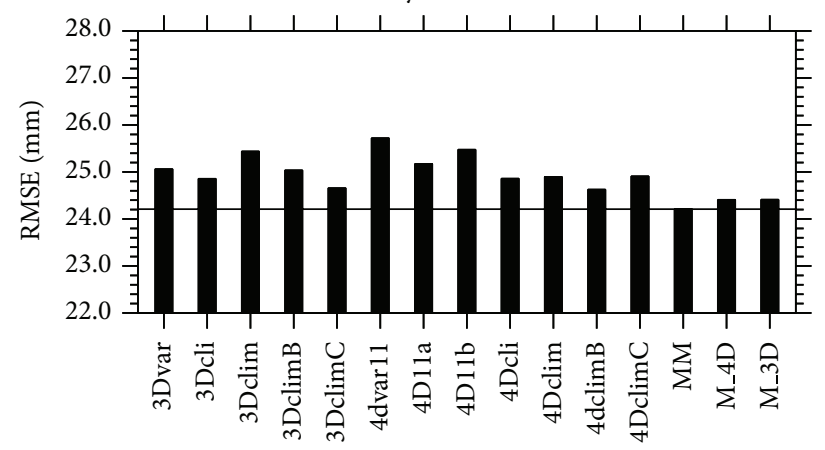

For daily rain $\geq 50 \mathrm{~mm}$

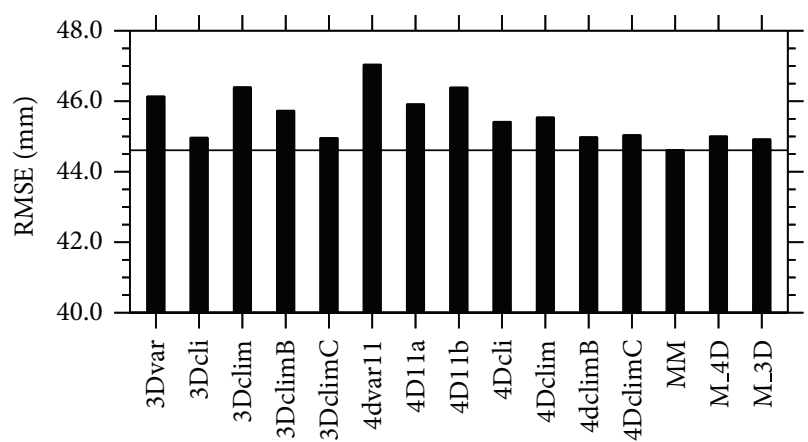

(a)

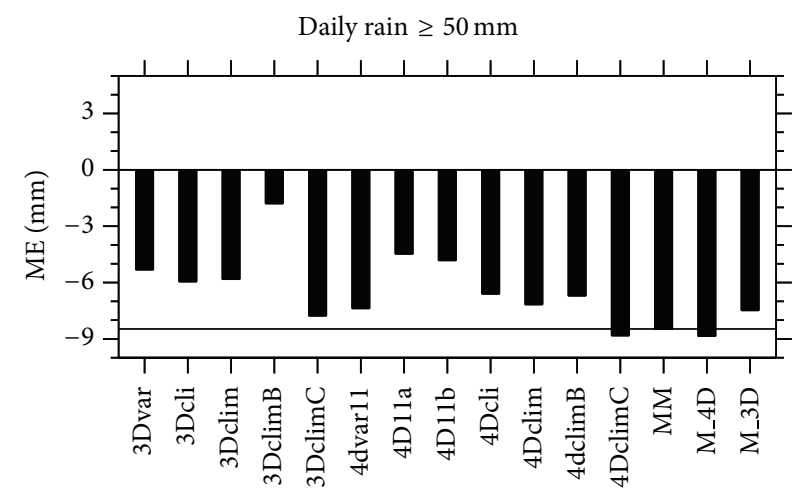

(b)

Figure 8: Root mean square errors (RMSE, (a)) and mean errors (ME, (b)) of daily rainfall at 630 stations for all simulations. Refer to Table 1 for the meaning of each member. MM denotes the ensemble mean of the 12 members. M_4D and M_3D denote the ensemble mean of the seven 4 Dvar members and the five 3Dvar members, respectively. The solid line denotes the value of MM, the same hereafter.

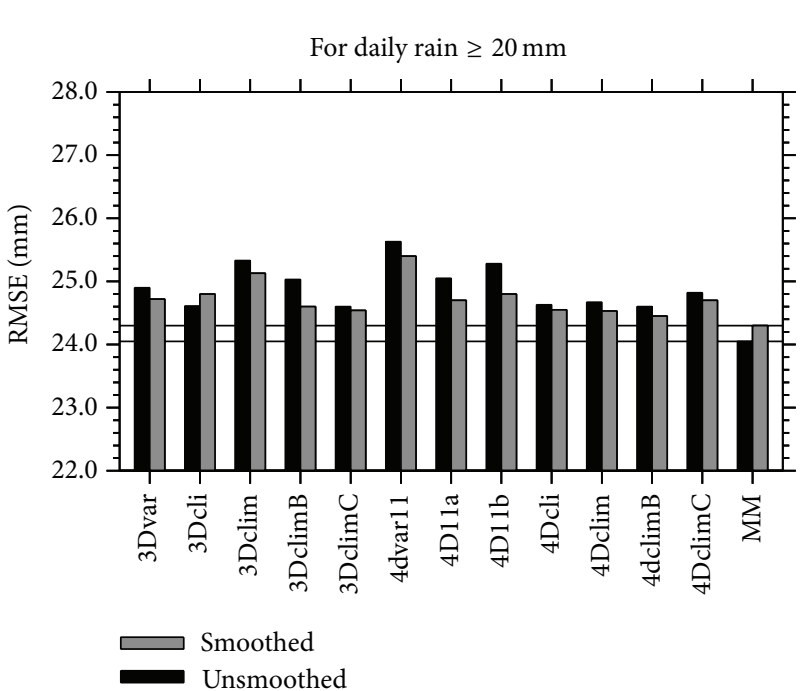

(a)

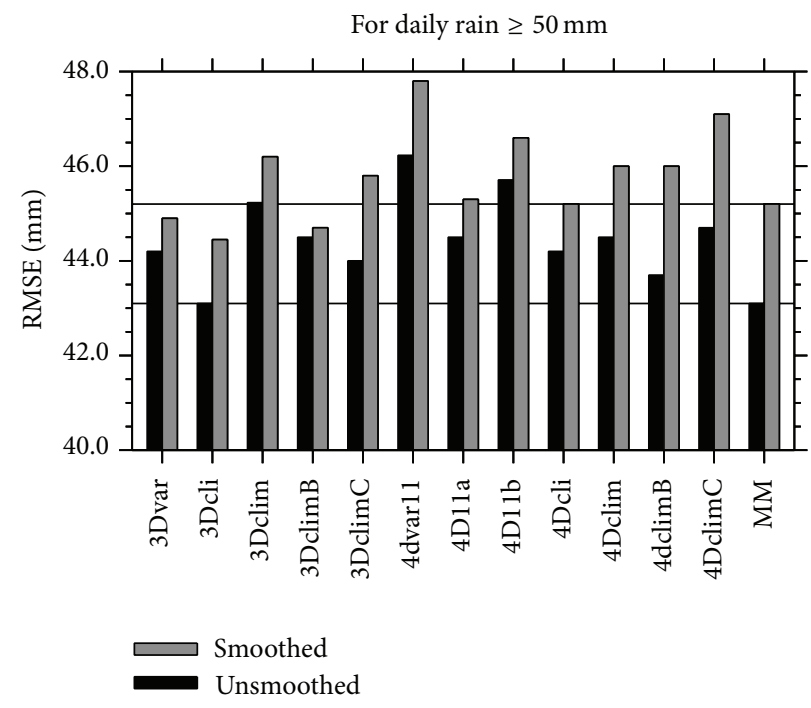

(b)

FIGURE 9: The RMSE of simulated (a) mod-heavy rainfall and (b) heavy rainfall for the whole country for smoothed forecasted rainfall (grey bars) using 9-point smooth three times and unsmoothed forecasted rainfall (dark bars). 

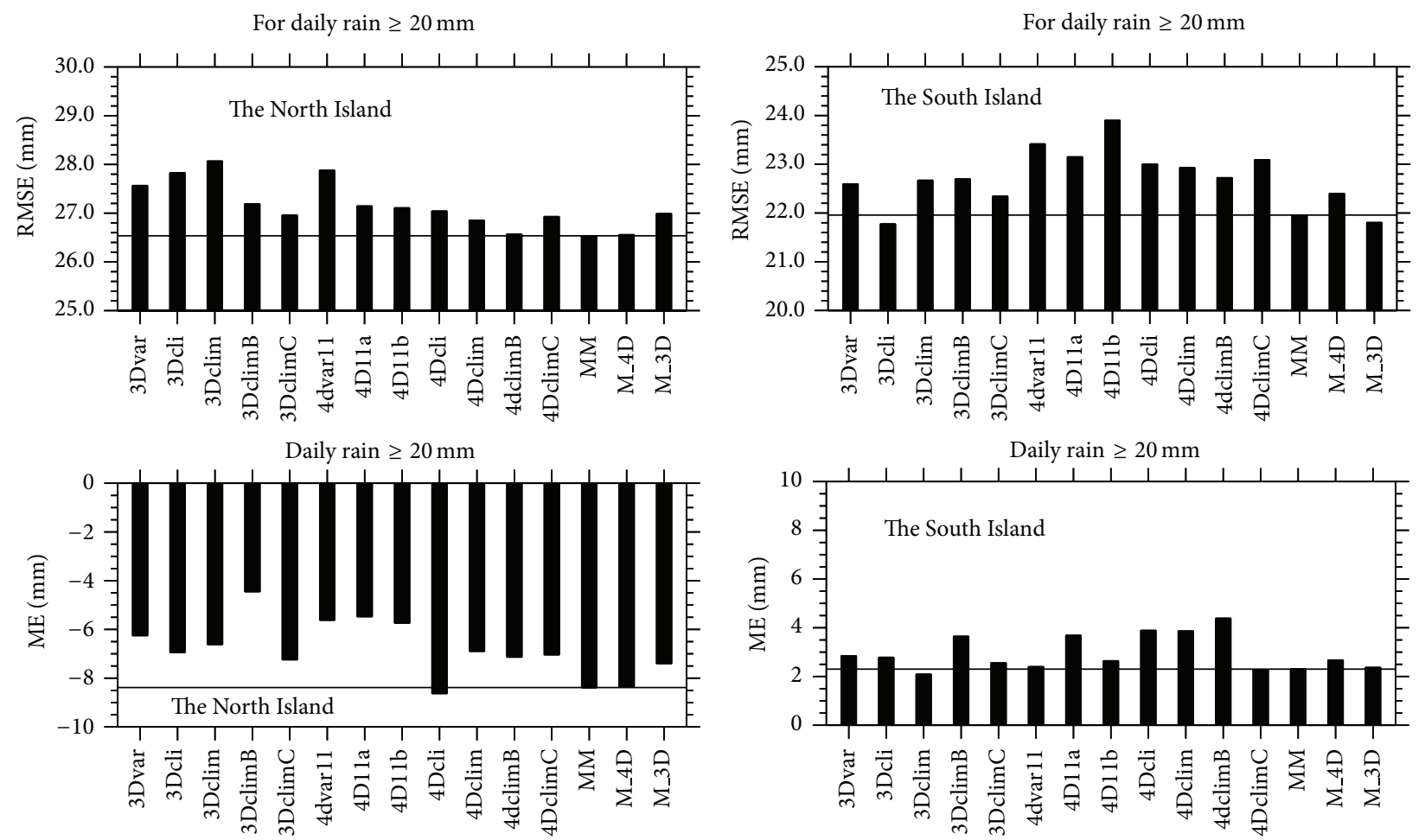

(a)

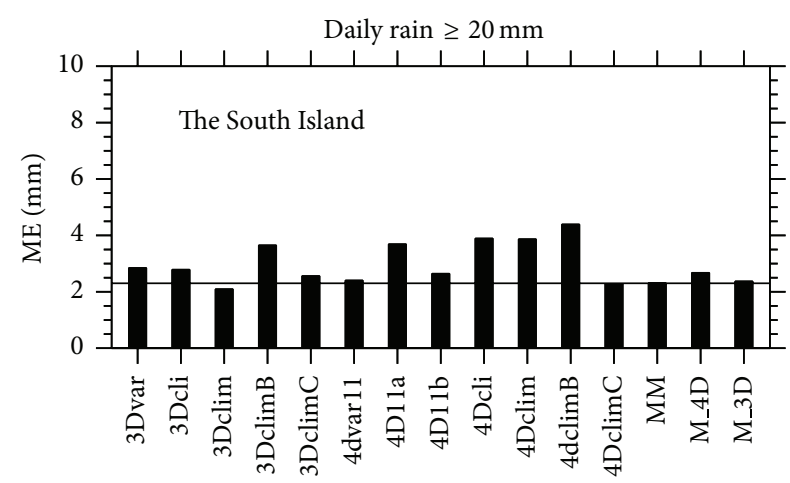

(b)

FIgURE 10: As in Figure 8 but for mod-heavy rainfall over the North Island (a) and over the South Island (b).

the forecasting skill analysis with only two rainfall categories to do the evaluation. Instead, RMSE and ME that can quantitatively show the real magnitude of rainfall forecasted errors are used.

For mod-heavy rainfall, the North Island had an RMSE of $26.5 \mathrm{~mm}$ for MM (Figure 10), whilst it was only $21.9 \mathrm{~mm}$ for South Island (Figure 10). For each member, the RMSE of rainfall was larger than $26.9 \mathrm{~mm}$ over the North Island; however, it was smaller than $23.5 \mathrm{~mm}$ for each member over the South Island. For mod-heavy rainfall, the ME of MM was $2.2 \mathrm{~mm}$ over the South Island, a positive bias much smaller than the negative bias $(-8.2 \mathrm{~mm})$ over the North Island. The magnitude of ME was almost the same for each member and the MM. For mod-heavy rainfall, ME accounted for more than $20 \%$ of the RMSE over the North Island, but only about $10 \%$ of the RMSE over the South Island.

For heavy rainfall (Figure 11), the RMSE of the MM was $50.0 \mathrm{~mm}$ over the North Island, whilst it was only $36.9 \mathrm{~mm}$ for the South Island. The RMSE for each member was more than $50.5 \mathrm{~mm}$ over the North Island, whilst it was smaller than $40.5 \mathrm{~mm}$ over the South Island. ME was $2.5 \mathrm{~mm}$ over the South Island, a bias much smaller than that $(-24 \mathrm{~mm})$ over the North Island. The ME of each member and the MM accounted only about $10 \%$ of the RMSE over the South Island, but about $40 \%$ of the RMSE over the North Island.

In terms of RMSE and ME, the ensemble system performed better over the South Island than over the North Island for both mod-heavy and heavy rainfall. Over the North Island, the pronounced negative bias of the simulated rainfall is a major factor leading to the worse performance of the ensemble. As described earlier, a major difference between the North Island and the South Island is the shape, height, and horizontal scale of mountains. These results indicate that mountains can significantly affect the performance of the ensemble system in moderate to heavy rainfall prediction and will be further discussed in the following section.

\section{Discussion}

The shape (horizontal aspect ratio and mountain height) of mountains affects the patterns and regimes of airflow past mountains [29-32] and significantly affects rainfall amount and rainfall distribution (e.g., [33-36]). As described earlier, the South Island has a relatively uniform mountain range (the Southern Alps), running some $600 \mathrm{~km}$ down the length of South Island and covering more than half its width, which the prevailing westerly airflow has to cross (Figure 1(b)). In contrast, the North Island has multiple ranges of hills and mountains giving it fewer clear-cut windward or lee side regions (Figure 1(a)). The spatial scales of the mountains of the North Island are smaller than those of the Southern Alps; as a result, a better description of mountain dynamic forcing (e.g., orographic lifting) exists for the latter in NZLAM $(12 \mathrm{~km}$ resolution) than for the former. In addition, circulations associated with airflow past a larger mountain tend to have larger spatial scale. This leads to better description of the air flow patterns forced by the Southern Alps than those forced by the mountains of the North Island, in NZLAM. Thus, 

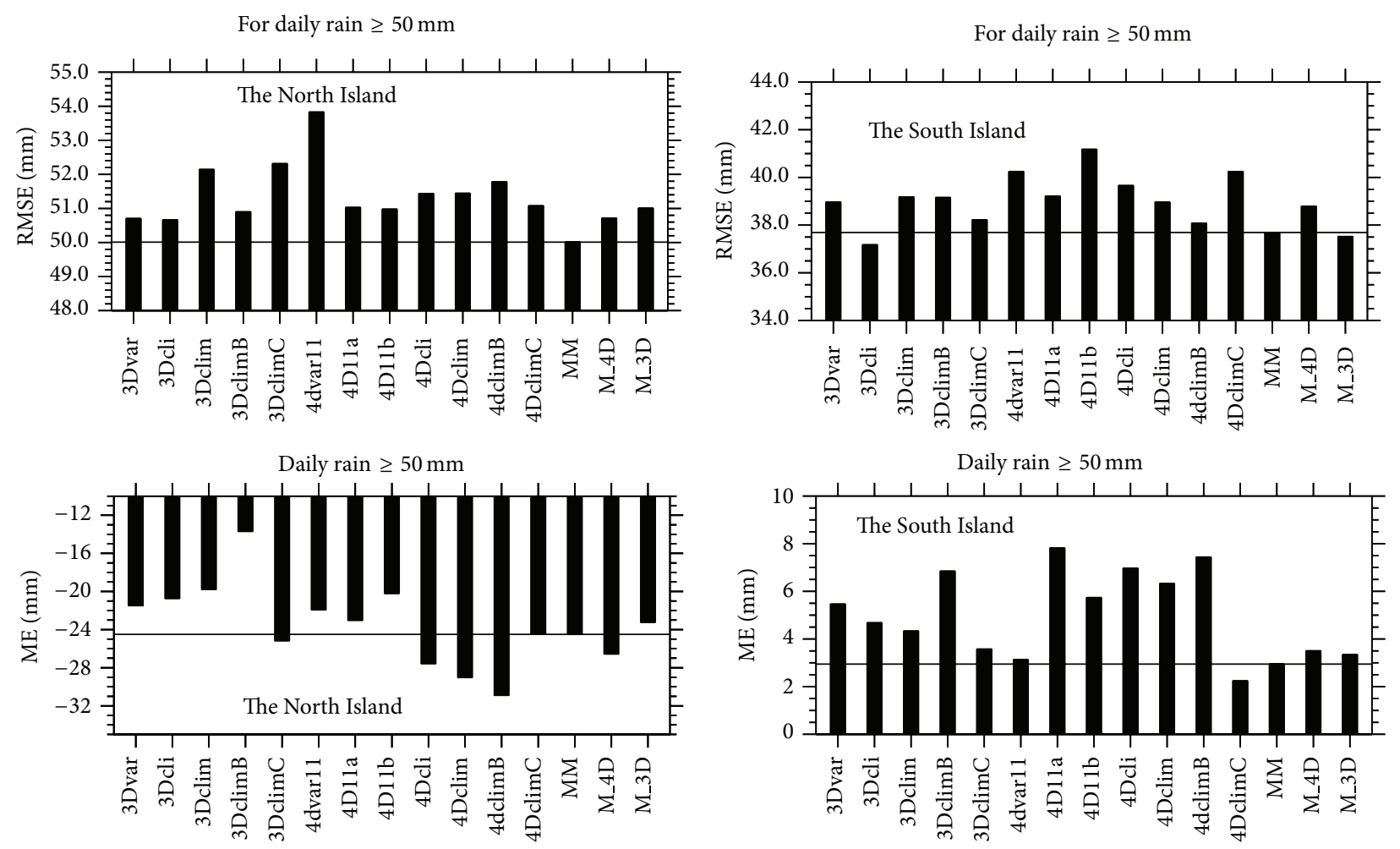

(a)

(b)

FIGURE 11: As in Figure 8 but for heavy rainfall over the North Island (a) and over the South Island (b).

the Southern Alps having uniform shape and larger spatial scales compared to the mountains of the North Island is most likely the reason for the better performance of the ensemble for the South Island.

In New Zealand, orographic lifting plays an important role in heavy rainfall occurrence. As described earlier, large negative biases of simulated moderate to heavy rainfall were found over the North Island and accounted for $20-40 \%$ of the errors. This suggests that, for the current resolution $(\sim 12 \mathrm{~km})$ of NZLAM, the orographic lifting was underestimated for the North Island. In fact, even for the South Island, relatively large RMSE and ME were found for mod-heavy and heavy rainfall as described earlier. Part of the rainfall prediction errors was due to the rainfall prediction bias, especially for heavy rainfall. Revell et al. [37] indicated that a resolution of $5 \mathrm{~km}$ or higher would be needed to adequately describe the vertical motion forcing of the mountains. Therefore, a higher model resolution (preferably $\leq 5 \mathrm{~km}$ ) than $12 \mathrm{~km}$ is needed for a New Zealand operational RES system for heavy rainfall prediction.

\section{Conclusion}

In this study, 12 experiments using the state of the art 3 Dvar and 4 Dvar techniques were combined as a temporary regional ensemble system. This is the first attempt at conducting ensemble prediction of rainfall directly from a regional weather modelling system in New Zealand. The objective is to investigate the effect of data assimilation and ensemble method on moderate and heavy rainfall forecasts and the effect of mountains on the performance of a RES in New Zealand.

The RMSE, ME, and several categorical verification metrics for daily rainfall were analysed based on two thresholds, $20 \mathrm{~mm}$ (mod-heavy rainfall) and $50 \mathrm{~mm}$ (heavy rainfall). In total 630 sites in New Zealand with daily rainfall observations were used. These analyses showed that, at the same model resolution, the simple ensemble performs better than any of the 12 experiments for mod-heavy rainfall prediction. The overall better performance of the ensemble was also found for heavy rainfall. Two heavy rainfall cases showed that, in most areas with heavy rainfall, the ensemble showed a high probability of occurrence $(\geq 0.6)$, due to the significant effect of mountains on heavy rainfall occurrence in New Zealand. This suggested that ensemble prediction of heavy rainfall using ensemble mean and occurrence probability would be a useful tool in New Zealand.

Under the prevailing westerly airflow for most time of a year, much rainfall occurs on the west side of the country, especially for the South Island with a steep west mountain slope that has a southwest-northeast orientation. Our analyses indicated that mountains can significantly affect the performance of this ensemble system with smaller errors (or RMSE) and bias (or ME) of forecasted mod-heavy rainfall and heavy rainfall over the South Island than over the North Island. This result is nothing new, but it indicates that a $12 \mathrm{~km}$ 
model resolution of the current temporary ensemble system is not high enough to well predict heavy rainfall in New Zealand. A $\sim 5 \mathrm{~km}$ or higher model resolution is required for a better performance of an operational RES system in New Zealand for heavy rainfall prediction.

This work implies that for regional ensemble prediction of heavy rainfall in complicated mountainous areas, in addition to the initial conditions, model resolution also needs to be properly treated according to the mountain scales. For future research, a similar RES with higher model resolution ( $5 \mathrm{~km}$ or finer) will be conducted to search for the optimum resolution over New Zealand. Beyond accounting for the uncertainties in initial conditions using data assimilation, the RES will also account for uncertainties in the lower boundary conditions (including SST, soil moisture, and vegetation cover) and the lateral boundary conditions.

\section{Conflict of Interests}

The authors declare that there is no conflict of interests regarding the publication of this paper.

\section{Acknowledgments}

This research was carried out under research collaboration SC0128 with the UK Met Office and funded by the New Zealand Foundation for Research, Science and Technology under Contract C01X081. The authors thank the anonymous reviewers for comments that have helped them improve the quality of this paper.

\section{References}

[1] F. Molteni, R. Buizza, T. N. Palmer, and T. Petroliagis, "The ECMWF ensemble prediction system: methodology and validation," Quarterly Journal of the Royal Meteorological Society, vol. 122, no. 529, pp. 73-119, 1996.

[2] M. Leutbecher and T. N. Palmer, "Ensemble forecasting," Journal of Computational Physics, vol. 227, no. 7, pp. 3515-3539, 2008.

[3] Z. Toth and E. Kalnay, "Ensemble forecasting at NMC: the generation of perturbations," Bulletin of the American Meteorological Society, vol. 74, no. 12, pp. 2317-2330, 1994.

[4] Z. Toth and E. Kalnay, "Ensemble forecasting at NCEP and the breeding method," Monthly Weather Review, vol. 125, no. 12, pp. 3297-3319, 1997.

[5] S. L. Mullen and D. P. Baumhefner, "Monte Carlo simulations of explosive cyclogenesis," Monthly Weather Review, vol. 122, no. 7, pp. 1548-1567, 1994.

[6] P. L. Houtekamer and H. L. Mitchell, "Data assimilation using an ensemble Kalman filter technique," Monthly Weather Review, vol. 126, no. 3, pp. 796-811, 1998.

[7] A. Aksoy, F. Zhang, and J. W. Nielsen-Gammon, "Ensemblebased simultaneous state and parameter estimation with MM5," Geophysical Research Letters, vol. 33, no. 12, Article ID L12801, 2006.

[8] F. Zhang, Y. Weng, Y.-H. Kuo, J. S. Whitaker, and B. Xie, "Predicting typhoon morakot's catastrophic rainfall with a convection-permitting mesoscale ensemble system," Weather and Forecasting, vol. 25, no. 6, pp. 1816-1825, 2010.
[9] Y. Jung, M. Xue, G. Zhang, and J. M. Straka, "Assimilation of simulated polarimetric radar data for a convective storm using the ensemble Kalman filter. Part II: impact of polarimetric data on storm analysis," Monthly Weather Review, vol. 136, no. 6, pp. 2246-2260, 2008.

[10] A. Aksoy, D. C. Dowell, and C. Snyder, "A multicase comparative assessment of the ensemble Kalman filter for assimilation of radar observations. Part I: storm-scale analyses," Monthly Weather Review, vol. 137, no. 6, pp. 1805-1824, 2009.

[11] D. M. Barker, "Southern high-latitude ensemble data assimilation in the Antarctic Mesoscale Prediction System," Monthly Weather Review, vol. 133, no. 12, pp. 3431-3449, 2005.

[12] Z. Meng and F. Zhang, "Tests of an ensemble Kalman filter for mesoscale and regional-scale data assimilation. Part III. Comparison with 3DVAR in a real-data case study," Monthly Weather Review, vol. 136, no. 2, pp. 522-540, 2008.

[13] R. D. Torn and G. J. Hakim, "Performance characteristics of a pseudo-operational ensemble Kalman filter," Monthly Weather Review, vol. 136, no. 10, pp. 3947-3963, 2008.

[14] K. Sattler and H. Feddersen, "Limited-area short-range ensemble predictions targeted for heavy rain in Europe," Hydrology and Earth System Sciences, vol. 9, no. 4, pp. 300-312, 2005.

[15] F.-C. Chien, Y.-C. Liu, and B. J.-D. Jou, "MM5 ensemble mean forecasts in the Taiwan area for the 2003 Mei-Yu season," Weather and Forecasting, vol. 21, no. 6, pp. 1006-1023, 2006.

[16] T. N. Krishnamurti, M. K. Biswas, B. P. Mackey, R. G. Ellingson, and P. H. Ruscher, "Hurricane forecasts using a suite of large-scale models," Tellus Series A: Dynamic Meteorology and Oceanography, vol. 63, no. 4, pp. 727-745, 2011.

[17] P. A. Chessa, G. Ficca, M. Marrocu, and R. Buizza, "Application of a limited-area short-range ensemble forecast system to a case of heavy rainfall in the mediterranean region," Weather and Forecasting, vol. 19, no. 3, pp. 566-581, 2004.

[18] M. Vich and R. Romero, "Multiphysics superensemble forecast applied to Mediterranean heavy precipitation situations," Natural Hazards and Earth System Science, vol. 10, no. 11, pp. 23712377, 2010.

[19] Y. Yang, M. Uddstrom, M. Revell et al., "Numerical simulations of effects of soil moisture and modification by mountains over New Zealand in summer," Monthly Weather Review, vol. 139, no. 2, pp. 494-510, 2011.

[20] S. Webster, M. Uddstrom, H. Oliver, and S. Vosper, "A highresolution modelling case study of a severe weather event over New Zealand," Atmospheric Science Letters, vol. 9, no. 3, pp. 119128, 2008.

[21] Y. Yang, M. Uddstrom, M. Revell, P. Andrews, and R. Turner, "Amplification of the impact of assimilating ATOVS radiances on simulated surface air temperatures over canterbury by the Southern Alps, New Zealand," Monthly Weather Review, vol. 140, no. 4, pp. 1367-1384, 2012.

[22] F. Rawlins, S. P. Ballard, K. J. Bovis et al., "The met office global four-dimensional variational data assimilation scheme," Quarterly Journal of the Royal Meteorological Society, vol. 133, no. 623, pp. 347-362, 2007.

[23] S. Webster, A. R. Brown, D. R. Cameron, and C. P. Jones, "Improvements to the representation of orography in the Met Office Unified Model," Quarterly Journal of the Royal Meteorological Society, vol. 129, no. 591, pp. 1989-2010, 2003.

[24] T. Davies, M. J. P. Cullen, A. J. Malcolm et al., "A new dynamical core of the Met Office's global and regional modelling of the atmosphere," Quarterly Journal of the Royal Meteorological Society, vol. 131, no. 608, pp. 1759-1782, 2005. 
[25] A. C. Lorenc, S. P. Ballard, R. S. Bell et al., "The Met. Office global three-dimensional variational data assimilation scheme," Quarterly Journal of the Royal Meteorological Society, vol. 126, no. 570, pp. 2991-3012, 2000.

[26] M. J. P. Cullen, "A demonstration of cycled 4D-Var in the presence of model error," Quarterly Journal of the Royal Meteorological Society, vol. 136, no. 651, pp. 1379-1395, 2010.

[27] P. J. Roebber, "Visualizing multiple measures of forecast quality," Weather and Forecasting, vol. 24, no. 2, pp. 601-608, 2009.

[28] C. A. T. Ferro and D. B. Stephenson, "Extremal dependence indices: improved verification measures for deterministic forecasts of rare binary events," Weather and Forecasting, vol. 26, no. 5, pp. 699-713, 2011.

[29] R. B. Smith, "Hydrostatic airflow over mountains," Advances in Geophysics, vol. 31, pp. 1-41, 1989.

[30] P. K. Smolarkiewicz and R. Rotunno, "Low Froude number flow past three-dimensional obstacles. Part II: upwind flow reversal zone," Journal of the Atmospheric Sciences, vol. 47, no. 12, pp. 1498-1511, 1990.

[31] H. Ólafsson and P. Bougeault, "Nonlinear flow past an elliptic mountain ridge," Journal of the Atmospheric Sciences, vol. 53, no. 17, pp. 2465-2489, 1996.

[32] M. H. Bauer, G. J. Mayr, I. Vergeiner, and H. Pichler, "Strongly nonlinear flow over and around a three-dimensional mountain as a function of the horizontal aspect ratio," Journal of the Atmospheric Sciences, vol. 57, no. 24, pp. 3971-3991, 2000.

[33] Y. Yang and Y.-L. Chen, "Effects of terrain heights and sizes on island-scale circulations and rainfall for the island of Hawaii during HaRP," Monthly Weather Review, vol. 136, no. 1, pp. 120146, 2008.

[34] S.-H. Chen and Y.-L. Lin, "Orographic effects on a conditionally unstable flow over an idealized three-dimensional mesoscale mountain," Meteorology and Atmospheric Physics, vol. 88, no. 12, pp. 1-21, 2005.

[35] B. A. Colle, "Sensitivity of orographic precipitation to changing ambient conditions and terrain geometries: an idealized modeling perspective," Journal of the Atmospheric Sciences, vol. 61, no. 5, pp. 588-606, 2004.

[36] J. Stein, "Exploration of some convective regimes over the Alpine orography," Quarterly Journal of the Royal Meteorological Society, vol. 130, no. 597, pp. 481-502, 2004.

[37] M. J. Revell, J. H. Copeland, H. R. Larsen, and D. S. Wratt, "Barrier jets around the Southern Alps of New Zealand and their potential to enhance alpine rainfall," Atmospheric Research, vol. 61, no. 4, pp. 277-298, 2002. 

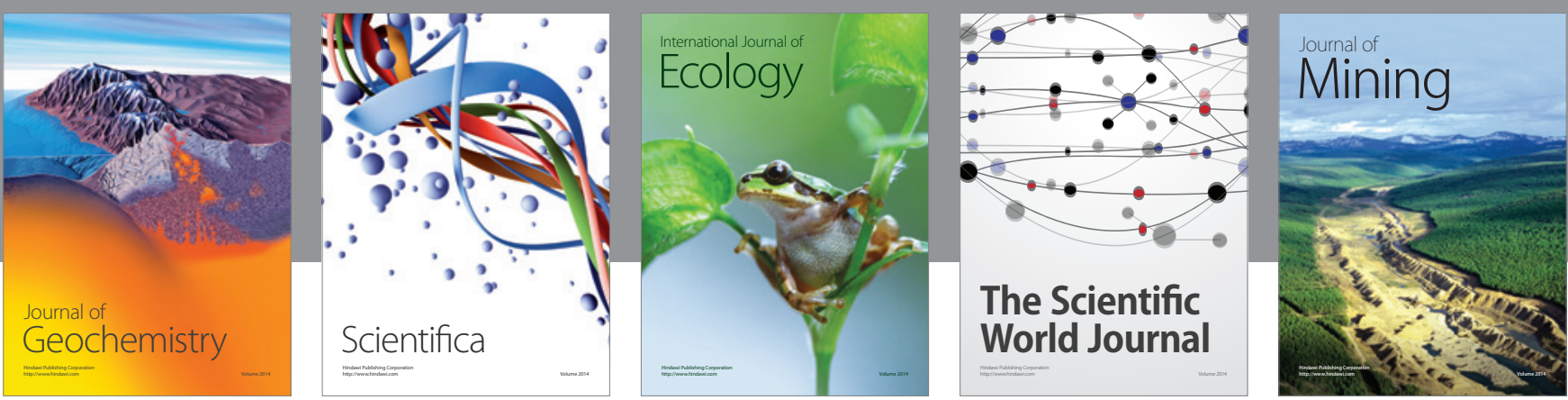

The Scientific World Journal
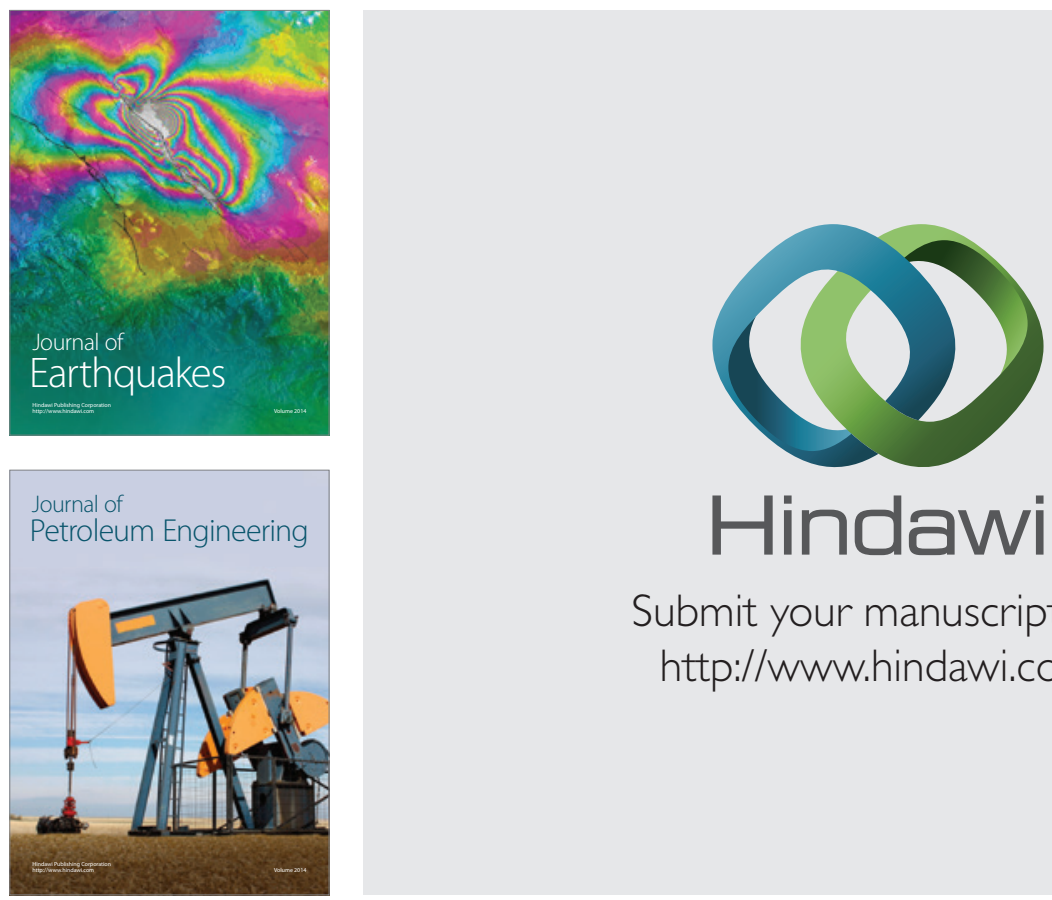

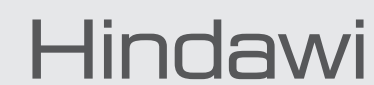

Submit your manuscripts at

http://www.hindawi.com
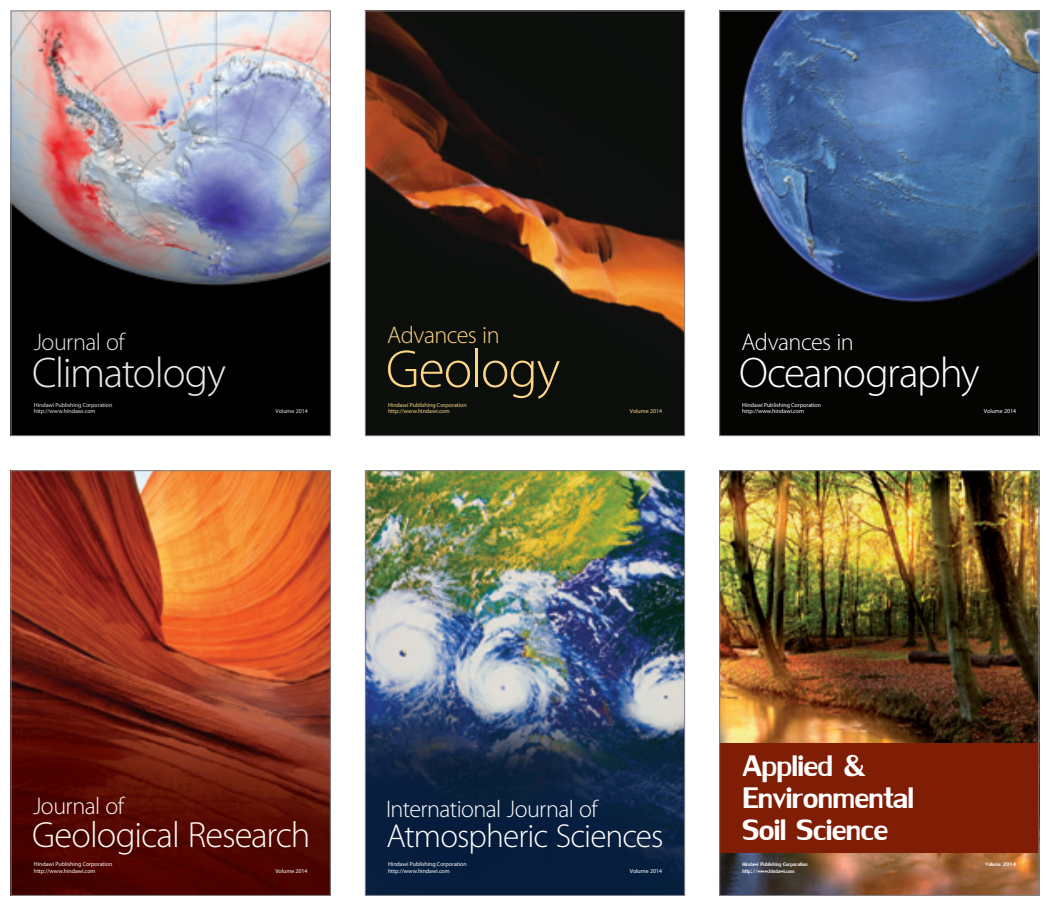
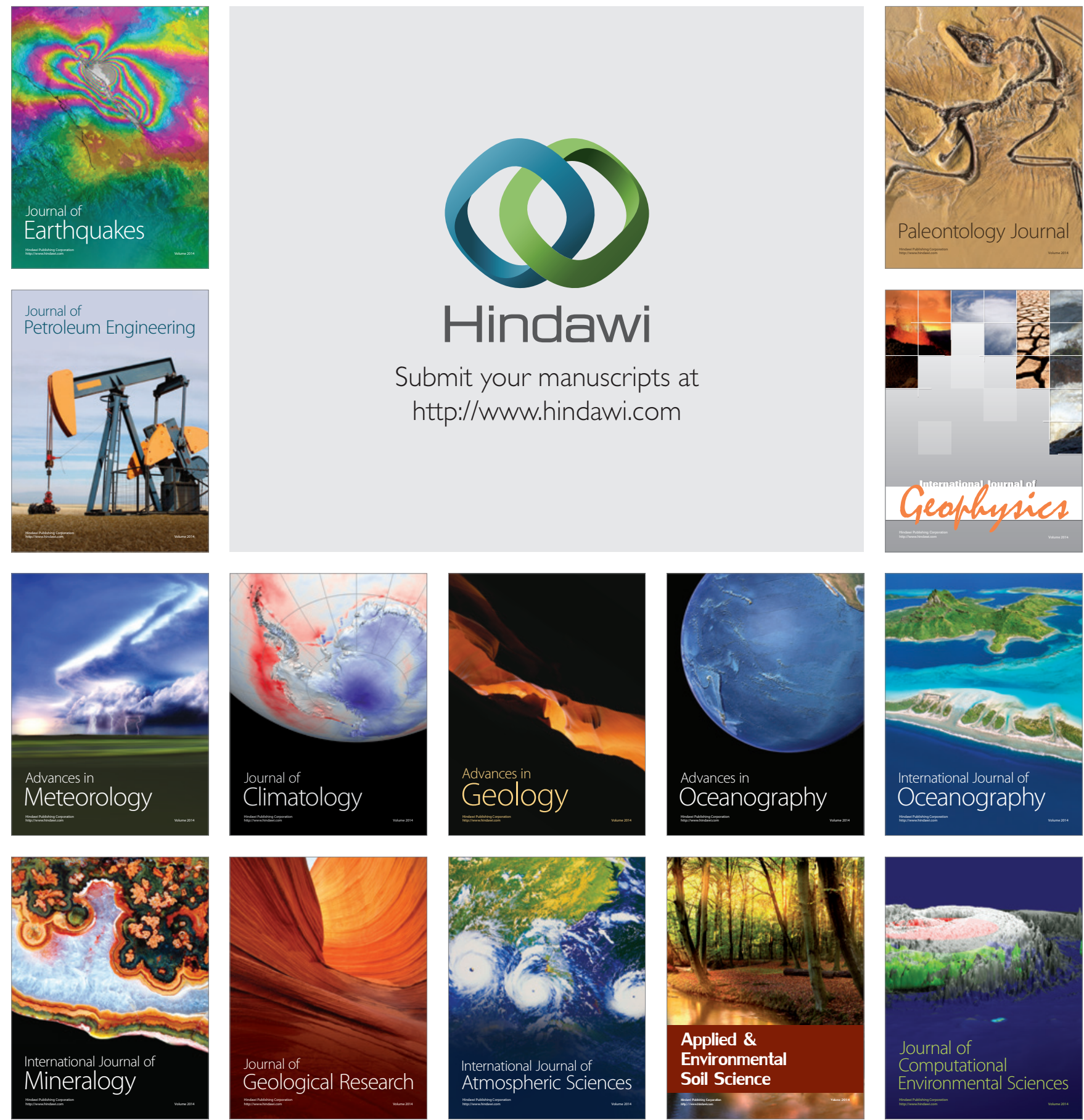